\title{
LAS CORPORACIONES DE CABALLEROS HIDALGOS EN LAS CIUDADES CASTELLANAS A FINES DE LA EDAD MEDIA. SU PARTICIPACIÓN EN EL EJERCICIO DEL PODER LOCAL ${ }^{1}$
}

\author{
MÁXIMO Diago HERNANDO \\ Instituto de Historia, CSIC. Madrid
}

Resumen: Se da cuenta de la existencia en numerosas ciudades castellanas en los siglos XV y XVI de asociaciones de caballeros hidalgos que tenían reconocido un destacado papel en la regulación del acceso al ejercicio del poder en el ámbito local. Se analiza el régimen de organización interno de algunas de estas asociaciones. Se da cuenta de la práctica del envío por parte de algunas de ellas de procuradores a los ayuntamientos de concejo, en representación del estamento privilegiado hidalgo. Y, en tercer lugar, se presta atención al papel desempeñado por algunas de ellas en los procesos de elección de determinados oficiales, como, por ejemplo, los regidores y los procuradores de Cortes.

Palabras clave: Corporaciones; Hidalgos; Baja Edad Media; Instituciones de gobierno local; Castilla.

\begin{abstract}
The author gives account of the existence in many Castilian towns during the fifteenth and sixteenth centuries of associations of noble urban knights, that played an important role in the regulation of the access to the exercise of power in the local scene. He analyses the way some of these associations were organised. Then he gives account of the fact that in many Castilian towns the privileged state of the urban nobles sent deputies to the assemblies of the town council. And finally he pays attention to the role played by some ot these associations of urban nobles in the election of several officers of local government, as, for example, the "regidores" (aldermen) and the Parliament deputies.
\end{abstract}

Keywords: Corporations; Nobles; Late Middle Ages; Institutions of local government; Castile

\section{SUMARIO}

I. Régimen de organización interna de las corporaciones de caballeros hidalgos. Algunos ejemplos ilustrativos: 1. Diputación de Doce Linajes de la ciudad de Soria. 2. Junta de Nobles Linajes de Segovia. 3. Cabildo de caballeros y escuderos de Cuenca.- II. Envío de representantes a las sesiones de ayuntamiento por las corporaciones de caballeros hidalgos.- III. Participación de las corporaciones de hidalgos en la designación de oficiales de gobierno local: 1. Procuraciones a Cortes. 2. Oficios de regidores vitalicios. 3. Otros oficios.- IV. Reactivación del papel político de las corporaciones de hidalgos en el período precomunero

${ }^{1} \mathrm{El}$ autor de este trabajo está integrado en el Grupo de Investigación validado por la Universidad Complutense de Madrid, identificado con el número 930369, y que responde a la denominación "Sociedad, Poder y Cultura en la Corona de Castilla. Siglos XIII al XVI". 
La nobleza urbana en la Corona de Castilla $^{2}$ tendió a constituir asociaciones propias de carácter marcadamente exclusivista, con el nombre de cofradías u otros similares, en prácticamente todas las ciudades en que sus efectivos alcanzaron un número mínimamente importante ${ }^{3}$. En bastantes casos estas cofradías no pasaron de ser agrupaciones basadas en la existencia de lazos de solidaridad con una fuerte proyección en la vida social urbana, pero sin ninguna reconocida atribución en el terreno político. En un importante número de ciudades, sin embargo, localizadas en su gran mayoría en la meseta, se consolidaron además otras asociaciones de hidalgos con explícito carácter estamental, que no sólo tuvieron proyección en el terreno social, sino que desempeñaron también un destacado papel en la vida política, que alcanzó incluso reconocimiento institucional.

Este tipo de asociaciones de nobles integrados en sociedades políticas urbanas, que tenían reconocida la capacidad de desempeñar un activo papel en el ejercicio del poder en el ámbito local, no proliferaron en el escenario europeo bajomedieval, entre otras razones porque en el mismo la figura del noble ciudadano no estuvo muy extendida. Desde bastantes puntos de vista pueden ser consideradas más bien como una peculiaridad castellana, aunque, por supuesto, también en otros ámbitos del continente, incluso en algunos con tradiciones jurídicas y modelos de organización política muy diferentes del castellano, pueden encontrarse instituciones que, al menos de forma parcial, presentan interesantes semejanzas con las mencionadas asociaciones de nobleza urbana de la Corona de Castilla. Por poner un único ejemplo, cabe recordar el caso de la célebre Richerzeche de la ciudad alemana de Colonia, por cuanto se trató de una asociación de carácter "privado", que agrupaba a un pequeño y selecto número de miembros del patriciado de esta capital renana, y al mismo tiempo ejerció durante los siglos XIII y XIV importantes funciones de carácter "público", entre las que cabe destacar la designación del Bürgermeister, el principal oficial de la institución de autogobierno urbano (Rat), que sólo tras la abolición de la referida asociación de patricios en 1391 pasó a ser un oficial concejil propiamente dicho ${ }^{4}$. Las diferencias entre esta

\footnotetext{
${ }^{2}$ Sobre la importancia alcanzada por la nobleza como estamento diferenciado dentro de la población de las ciudades castellanas bajomedievales, que contrasta con la situación vigente en otros ámbitos de la Europa bajomedieval, donde no se contemplaba que los nobles pudiesen integrarse en las estructuras sociopolíticas urbanas, Vid. Máximo DIAGO HERNANDO, El perfil integrarse en las estructuras sociopoliticas urbanas, la. Maximo DIAGO HerkNANDO, El perfil
socloeconomico de los grupos gobernantes en las ciudades bajomedievales. análisis
comparativo de los ejemplos castellano y alemán, "En la España Medieval", 18 (1995), pp. 85comparativo de los ejemplos castellano y alemán, "En la España Medieval", 18 (1995), pp. 85-

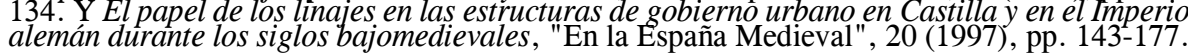

${ }^{3}$ Adelina ROMERO MARTÍNEZ, El asociacionismo del poder: Las cofradías de hidalgos y caballeros, "En la España Medieval", 18 (1995), pp. 135-162.

${ }^{4}$ Entre las numerosas obras de la bibliografía que tratan sobre la singular institución de la Richerzeche de Colonia, destacaremos como uno de los trabajos más recientes el de Ernst KRUSE, Die Kölner Richerzeche "Zeitschrift der Savigny Stiftung für Rechtsgeschichte. Germanische Abteilung", 9 (1988), pp. 152-209. Sobre la transformación del oficio de Bürgermeister en Colonia tras la disolución de la Richerzeche en 1391 vid. Wolfgang Bürgermeister en Colonia tras la disolucion de la Richerzeche en 1391 vid. Wolfgang
HERBORN, Verfassungsideal und Verfassungswirklichkeit in Köln während der ersten zwel HERBORN, Verfassungsideal und Verfassungswirklichkeit in Köln während der ersten zwel Jahrhunderte nach Inkrafttreten des Verbundbriefes von 1396 dargestellt am Beispiel des
Bürgermeisteramtes, en Wilfried EHBRECHT (ed.), Städtische Führungsgruppen und Gemeinde in der werdenden Neuzeit, Böhlau, Colonia-Viena, 1980, p. 28.
} 
peculiar institución coloniense y las asociaciones de nobles que tuvieron reconocidas funciones de gobierno en las ciudades castellanas bajomedievales son muchas. En concreto cabe destacar el hecho de que, pese a su carácter marcadamente exclusivista y aristocrático, la Richerzeche no fue una asociación de nobles propiamente dichos, puesto que desde el punto de vista jurídico sus miembros no se diferenciaban del resto de la población coloniense sino que todos formaban parte del mismo estamento, el ciudadano. Las organizaciones que encontramos en las ciudades castellanas de las que vamos a tratar aquí tenían por el contrario un marcado carácter estamental, y servían como plataforma que garantizaba un acceso privilegiado al ejercicio del poder en el ámbito local a los miembros del estamento noble, formalmente diferenciado en estas ciudades del estamento pechero, que disponía también de sus propias organizaciones estamentales.

Sobre la cuestión del desarrollo de instituciones de carácter corporativo que proporcionaban un marco de acción política y un elemento de identidad para los estamentos, y más en concreto para el privilegiado noble, en las ciudades castellanas de los siglos XIV, XV y XVI, ha reflexionado en los últimos años Pablo Sánchez León, para llegar a la conclusión de que este tipo de instituciones alcanzaron escasa difusión en la Corona de Castilla, porque las reformas institucionales impulsadas por Alfonso XI, que conllevaron la implantación del regimiento, no dieron lugar al reconocimiento de ningún tipo de identidad corporativa a los estamentos, y sólo en algunos pocos lugares concretos la reforma institucional en el ámbito local coincidió con un reconocimiento estamental expreso ${ }^{5}$. De hecho este autor sólo llega a constatar la existencia de este tipo de instituciones en las ciudades de Segovia y Zamora. Pero un somero repaso a las monografías de historia local publicadas en las últimas décadas, y de otras más antiguas, demuestra que el número de ciudades que las conocieron, en alguna de sus diversas variantes, fue mucho más numeroso.

Por ello hemos considerado de interés dedicar un breve trabajo a dar cuenta de la existencia de este tipo de asociaciones, para matizar la tesis, a nuestro parecer escasamente fundamentada, de Sánchez León sobre la falta de desarrollo de las corporaciones de carácter estamental en las ciudades castellanas bajomedievales, y llamar a su vez la atención sobre una peculiaridad del sistema político consolidado en muchas de estas ciudades durante el período bajomedieval, al que no resulta fácil encontrar paralelos en otros ámbitos de la Europa occidental. Trataremos de demostrar, por consiguiente, que, aparte de Segovia y Zamora, hubo otras muchas ciudades en que, paralelamente a la introducción de la institución del regimiento, se consolida-

${ }^{5}$ Pablo SÁNCHEZ LEÓN, La constitución histórica del sujeto comunero: Orden absolutista y lucha por la incorporación estamental en las ciudades de Castilla, 1350-1520, en Fernando MARTíNEZ GIL (Coord.), En torno a las Comunidades de Castilla. Actas del Congreso MARTINEZ GIL (Coord.), En torno a las Comunidades de Castilla. Actas del Congreso Universidad de Castilla la Mancha, pp. 182 y ss. También mantiene esta misma tesis en su monografía Absolutismo y comunidad. Los origenes sociales de la guerra de los comuneros de Castilla, Siglo XXI, Madrid, 1998 
ron corporaciones que agrupaban a los miembros del estamento privilegiado, las cuales desempeñaron por diferentes vías un destacado papel en la vida política local, que, no obstante, fue decayendo de forma generalizada conforme los regidores avanzaron en la persecución del objetivo de monopolizar y patrimonializar en sus familias el ejercicio del poder en el ámbito local. Este proceso no tuvo, sin embargo, un carácter lineal, y así lo demuestra la intensificación del desafío lanzado a estos regidores desde las corporaciones de nobleza urbana en muchas ciudades castellanas durante las dos primeras décadas del siglo XVI, que alcanzó su culminación en los meses de la revuelta comunera. Y a este interesante período de despliegue de activismo político desde las corporaciones de nobleza urbana dedicaremos especial atención en el presente trabajo, por tratarse de uno de los mejor documentados, y al mismo tiempo de los peor estudiados, de la historia castellana, quizás por su carácter de fase transitoria entre el mundo medieval y el moderno.

\section{RÉGIMEN DE ORGANIZACIÓN INTERNA DE LAS CORPORACIONES DE CABALLEROS HIDALGOS. ALGUNOS EJEMPLOS ILUSTRATIVOS.}

Las corporaciones de nobleza urbana que tuvieron reconocida la capacidad de desempeño de funciones políticas no presentaron características uniformes en todas las ciudades castellanas donde se desarrollaron durante los siglos XIV y XV, sino que, por el contrario, se pueden advertir notables diferencias entre unas y otras. La falta de estudios, por otra parte, dificulta la tarea de realizar un análisis comparativo de todas ellas, orientado a determinar disparidades y coincidencias. Por ello nos vamos a limitar aquí a ofrecer unos pocos ejemplos ilustrativos que nos permitan conocer con un cierto detalle algunas corporaciones en particular.

\section{Diputación de Doce Linajes de la ciudad de Soria}

Entre las corporaciones de nobleza urbana que llegaron a alcanzar un mayor desarrollo institucional y proyección política y social en la Castilla bajomedieval, y mantuvieron su influencia, aunque cada vez más mermada, hasta el fin del Antiguo Régimen, cabe destacar la Diputación de los Doce Linajes de la ciudad de Soria. Fue sin ningún género de duda una corporación con fuerte presencia en la vida política y social soriana desde el siglo XIV hasta comienzos del siglo XIX, y buena prueba de ello nos la proporciona el hecho de que el actual edificio del ayuntamiento constitucional de la ciudad de Soria se levanta sobre el solar ocupado con anterioridad por el edificio donde tuvo su sede esta institución, en el cual llegó a edificarse un patio de comedias, donde se realizaron representaciones teatrales durante los siglos XVII y XVIII.

La Diputación agrupaba a los doce linajes de caballeros hidalgos de la ciudad de Soria, que tenían entidad propia, y eran los que, cada uno por sí, 
desempeñaban un activo papel en la vida política soriana, en los procesos de nombramiento de numerosos oficiales, desde los de mayor rango, como regidores y procuradores en Cortes, hasta los más modestos, como era el caso de los guardas de los montes y términos, conocidos con el nombre de montaneros ${ }^{6}$. La Diputación como tal no desempeñaba, por tanto, un papel político relevante, pero en el plano social alcanzaba una enorme proyección como consecuencia de la labor de beneficiencia que realizaba. Disponía, en efecto, de un patrimonio propio, constituido por tierras, cedidas en su mayor parte a censo, y por las iglesias de La Cruceja y La Tablada ${ }^{7}$. Este patrimonio le confería identidad como institución, y era a la vez el que le permitía asumir el desempeño de la aludida labor benéfica, que se concretaba en el sostenimiento del hospital de Sancti Spiritus, especializado en la acogida de niños expósitos abandonados por sus progenitores tras su nacimiento. En efecto, todos los ingresos generados por la explotación de dicho patrimonio, en su mayor parte rentas en cereal pagadas por campesinos de la Tierra de Soria que tomaban a censo tierras de labranza, eran destinados a sufragar los gastos a los que tenía que hacer frente este hospital. Y para la administración tanto del patrimonio como del hospital la Diputación designaba cada año un mayordomo, oficio que correspondía desempeñar a un caballero hidalgo elegido por rotación entre los miembros de los doce linajes. Éste debía rendir cuentas de su gestión ante los diputados nombrados por cada uno de los doce linajes, que eran conocidos con el nombre de "diputados de los arneses", porque entre sus funciones estaba la de gestionar el reparto de los cien arneses que, en virtud de un privilegio a los caballeros sorianos atribuido a Alfonso VIII, debía entregar a estos caballeros cada monarca castellano al comienzo de su reinado ${ }^{8}$. Estos arneses probablemente representaron en un primer momento el principal factor aglutinador que hizo posible la consolidación de la institución de la Diputación de los Doce Linajes, y en torno a ellos se iría conformando en el transcurso de las generaciones el importante patrimonio fundiario que llegó a acumular esta última, por virtud de donaciones. Y por esta razón los representantes de los doce linajes designados para supervisar la gestión de dicho patrimonio serían conocidos con el nombre de "diputados de los arneses".

Según la tradición, habían sido algunos caballeros sorianos los fundadores del hospital de Sancti Spiritus, los cuales habían donado para ello a la Diputación de los Doce Linajes algunas heredades, con la condición de que las rentas generadas por su explotación se destinasen al sostenimiento de

${ }^{6}$ Sobre el papel de los Doce Linajes sorianos en la elección de oficiales Vid. Máximo DIAGO HERNANDO, Introducción a la historia institucional del concejo de Soria en la Baja Edad Media, "En la España Medieval", 11 (1988), pp. 23-43.

${ }^{7}$ Una relación exhaustiva de las heredades que formaban parte del patrimonio de la Diputación de los Doce Linajes en un manuscrito fechado alrededor del año 1571 , del que es autor el escribano Alonso Martínez, en Archivo Municipal de Soria Linajes, no ${ }^{\circ} .5$.

${ }^{8}$ No se conserva el privilegio original de Alfonso VIII sino sólo su confirmación por Sancho IV, en Valladolid, 12-V-1285. El documento ha sido publicado pro J. LOPERRAEZ CORVALÁN, Descripción histórica del obispado de Osma, Turner, Madrid, 1978 (facsímil de la primera edición de 1788), vol. III, pp. 221-2. 
los niños expósitos de Soria y su Tierra. El hecho, no obstante, de que dicho hospital se colocase bajo la advocación de Sancti Spiritus dio lugar a que durante el reinado de los Reyes Católicos se llegasen a plantear algunos problemas en torno a la asignación de su titularidad. Así, en concreto, en 1500 los caballeros sorianos manifestaron ante los reyes su temor a que los frailes de la Orden llamada de Sancti Spiritus consiguiesen que en Corte romana se les diese posesión de dicho hospital y se apoderasen por esta vía de sus rentas, que desde tiempo inmemorial venía administrando el mayordomo nombrado por la Diputación de Doce Linajes ${ }^{9}$. Y, en parte, dicho temor se vio más adelante justificado, pues sabemos que en 1508 se presentó en Soria un tal Juan Díaz de Granón con la pretensión de que se le había proveído por el maestre de la Orden de Sancti Spiritus de la administración de la casa y hospital que bajo esta advocación existía en esta ciudad. Pero no logró tomar posesión de ella, porque se encontró que ciertas personas legas la tenían tomada y habían encastillado su iglesia ${ }^{10}$. Y en adelante no tenemos constancia de que la Diputación de Doce Linajes volviese a ver cuestionada su condición de patrona y administradora del hospital de niños expósitos de Sancti Spiritus hasta su disolución en el siglo XIX, para el cual buscó incluso a lo largo de la Edad Moderna otras fuentes adicionales de financiación. Entre ellas merecen destacarse los ingresos generados por la representación de obras teatrales en un corral de comedias que la Diputación hizo construir en el edificio donde tenía fijada su sede institucional en Soria, en la Plaza Mayor, en el solar donde actualmente se ubica el ayuntamiento ${ }^{11}$.

El notable grado de desarrollo institucional alcanzado por la Diputación de los Doce Linajes, que, además de dotarles de identidad, proporcionó a los miembros del estamento privilegiado de Soria y su Tierra una magnífica plataforma desde la que poder controlar el acceso al ejercicio del poder local, no impidió, sin embargo, que en esta ciudad se desarrollasen también otras asociaciones reservadas para los miembros del dicho estamento, que, a diferencia de aquélla, no tuvieron proyección política, pero sî́ desempeñaron un muy activo papel en la vida social. Entre dichas asociaciones cabe destacar la cofradía de Santa Catalina, en la que sólo podían ingresar 1500.

${ }^{9}$ Vid. AGS (=Archivo General de Simancas), RGS (= Registro General del Sello), VIII-

${ }^{10} \mathrm{AGS}, \mathrm{RGS}, \mathrm{II}-1508$. Documento publicado por E. COOPER, Castillos señoriales de Castilla. Siglos XV y XVI, Madrid, 1981, vol. II, apéndice documental, $\mathrm{n}^{\circ} .289$.

${ }^{11}$ No se dispone de investigaciones que hayan abordado el estudio del funcionamiento del corral de comedias como fuente de financiación de la obra benéfica de los niños expósitos en la ciudad de Soria. A título ilustrativo nos limitaremos a recordar que en 1671 dos diputados de los arneses del estado de los doce linajes firmaron un contrato con un maestro de carpintería para que éste fabricase "el teatro, coliseo y patio de las comedias, dentro del que tiene la casa de los doce linajes". AHPS (=Archivo Histórico Provincial de Soria), PN (=Protocolos Notariales) 781-1265-200 Soria 10-X-1671. Por un documento Soria), PN (= Protocolos consta que la Diputación de los Doce Linajes nombraba un "comisario del patio de comedias" consta que la Diputación de los Doce Linajes nombraba un "comisario del patio de comedias", y para entonces dicha institución había hecho cesión "en forma del útil" del referido patio de comedias a favor del hospital de niños expósitos, para contribuir a la manutención de éstos, habiéndose formalizado la cesión mediante una escritura pública que había sido confirmada después por el Consejo de Castilla por real provisión. Vid. AHPS, PN, 1036-1601-410, Soria, 8-VIII-1724. 
los hidalgos, y que por este motivo fue durante los siglos XV, XVI y XVII la más prestigiosa de la ciudad de Soria, siempre requerida para ensalzar con la presencia de sus símbolos y de sus miembros las ceremonias religiosas organizadas con ocasión de los fallecimientos de los personajes pertenecientes a los sectores más encumbrados de la población soriana ${ }^{12}$. A ella se intentó añadir en la segunda mitad del siglo XVI otra cofradía de signo igualmente elitista, colocada bajo el patrocinio del apóstol Santiago, el santo preferido como patrón por las cofradías de caballeros hidalgos erigidas en la Castilla bajomedieval, y que se marcó por objetivo revitalizar las decaídas prácticas de la caballería, mediante la celebración de múltiples actos religiosos y ceremonias caballerescas a lo largo del año, y muy en particular en las festividades de San Juan, Santiago y Virgen de Agosto. Pero este proyecto no prosperó $^{13}$, y como consecuencia la cofradía de Santa Catalina continuó proporcionando a los miembros del estamento pivilegiado laico de la ciudad de Soria el principal marco para anudar lazos de sociabilidad entre sí, y proyectar sobre el escenario social local su preeminente posición.

\section{Junta de Nobles Linajes de Segovia}

Al igual que la Diputación de Doce Linajes de Soria, la Junta de Nobles Linajes de Segovia dispuso de un patrimonio propio que sin duda contribuyó decisivamente a su consolidación como institución y a su pervivencia a lo largo de los siglos, incluso después de haber perdido la mayor parte de sus atribuciones políticas. En concreto desde esta perspectiva se ha de destacar el hecho de que desde el período bajomedieval quedó establecido un condominio de la Junta y el concejo segoviano sobre los pinares de Valsaín, en virtud del cual los provechos obtenidos de su explotación se debían repartir por mitad entre las dos instituciones. Y estos provechos no eran en absoluto insignificantes, pues, según nos informa la profesora Asenjo, en 1507 el concejo segoviano ingresó por su mitad 96.250 mrs. y en 1510 la cifra ascendió a 107.000 mrs. ${ }^{14}$.

Nada hemos conseguido averiguar, sin embargo, sobre la dedicación dada por la Junta a éstos y otros posibles ingresos de los que pudo disponer, ni sobre cómo los administraba. No tenemos constancia de que tuviese a su cargo alguna obra benéfica, aunque tampoco habría que descartarlo. En cualquier caso queda mucho por averiguar sobre el régimen de funcionamiento de esta institución, a la que, a diferencia de la Diputación de los Doce Linajes

\footnotetext{
${ }^{12}$ Breves notas sobre la historia de esta cofradía en Máximo DiAgo HeRnANDo, Soria y su Tierra en el obispado de Osma durante los siglos XV y XVI. Organización eclesiástica y práctica religiosa, "XIV Centenario Diócesis Osma-Soria. Premios de Investigación", Diputación Provincial, Soria, 2000, pp. 565-6.

${ }^{13} \mathrm{Vid} . \mathrm{M}^{\mathrm{a}} \mathrm{A}$. SOBALER SECo, La cofradía de nobles caballeros de Santiago de Soria (1572): Un intento frustrado de corporativismo nobiliar, "Investigaciones Históricas", 12 (1992), pp. 11-29.

${ }^{14}$ Vid. M ${ }^{a}$ AsEnjo GonZÁLEZ, Segovia. La ciudad y su Tierra a fines del Medievo, Segovia, 1986, p. 463.
} 
de Soria, nos consta que se le pusieron muchas más trabas para su plena consolidación, por el temor que alimentaban los regidores a que fuese utilizada como plataforma para coordinar la oposición a su labor de gobierno por parte de los hidalgos que no tenían acceso al regimiento. Así, sabemos que en los últimos años del siglo XV tanto desde la Junta de Nobles Linajes como desde la Comunidad de pecheros de la ciudad se puso en marcha una intensa campaña reivindicativa ante las instituciones de gobierno de la monarquía para conseguir el reconocimiento a ambas instituciones del libre derecho de reunión, pues en los dos casos lo tenían entonces fuertemente limitado. En concreto, por lo que se refiere a los linajes, éstos sólo estaban autorizados a efectuar tres reuniones al año: el día de año nuevo para nombrar las personas que se habían de reunir con los regidores para tratar sobre las rentas de Valsaín; el día de San Martín para nombrar repartidores, y el día de San Lázaro para nombrar fieles ${ }^{15}$. En 1498 solicitaron a los reyes que se les permitiese reunirse cuando lo estimasen oportuno, y que en sus reuniones no pudiesen estar presentes los regidores, para estar en condiciones de discutir con más libertad sobre los agravios que éstos les causaban a los hidalgos, considerando que bastaba con que presidiese algún oficial de la justicia, de nombramiento regio, para garantizar el mantenimiento del orden. Pero los regidores reaccionaron de forma inmediata solicitando a los reyes que no accediesen a esta solicitud, argumentando que si se autorizasen los nuevos ayuntamientos en las condiciones propuestas equivaldría a que hubiese en la ciudad "dos regimientos e dos cabeças", y recordando a su vez que en las pocas reuniones que estaban autorizados a efectuar los linajes se producían habitualmente desórdenes, de modo que si les permitía reunirse cuando quisiesen el problema se agravaría, y resultaría muy difícil mantener el orden público ${ }^{16}$.

Por lo demás, los trabajos de investigación disponibles dejan sin respuesta muchas cuestiones relativas al perfil institucional de la Junta y su evolución, hasta el punto de que se plantea la duda sobre en qué medida ésta tenía entidad propia, o los que la tenían era cada uno de los dos linajes por su lado, que apenas realizarían esfuerzos por dotarse de un mínimo aparato institucional compartido y común, que garantizase la persecución de unos mismos objetivos políticos de una forma continuada. Así, por ejemplo, en este sentido cabe destacar que nos consta que cada uno de los linajes tenía su propio escribano ${ }^{17}$, pero por el contrario no tenemos noticia de que además hubiese un escribano de la Junta, que levantase acta de los acuerdos tomados en sus asambleas.

\footnotetext{
${ }^{15}$ Ibídem, p. 293.

${ }^{16}$ Ibídem, p. 635

${ }^{17}$ M. ASENJO, op . cit. pp. 581-3. Relación de miembros de los linajes de Ferrand García y Día Sánchez, reunidos a pregón, en Segovia, 19-V-1466. 


\section{Cabildo de caballeros y escuderos de Cuenca}

El tercer ejemplo de corporación estamental que hemos seleccionado para esta breve muestra, el del cabildo de caballeros y escuderos de Cuenca, presenta importantes diferencias con los dos anteriores, por cuanto no participa del carácter de agregación de asociaciones con fuerte identidad propia que tenían tanto la Junta de Nobles Linajes segoviana como la Diputación de Doce Linajes soriana. Además se trataba de una corporación de origen al parecer bastante más reciente, pues las primeras menciones a la misma datan de la primera mitad del siglo $\mathrm{XV}^{18}$, mientras que los linajes sorianos y segovianos pueden retrotraer sus orígenes al menos hasta la primera mitad del siglo XIV, aunque la Junta y la Diputación es probable que adquiriesen su perfil institucional definitivo algo más tarde. Y, por otra parte, también le confirió una indiscutible singularidad el hecho de que coexistió con otra corporación estamental que agrupaba a un sector de la población también privilegiado, aunque en menor grado que sus miembros, como era el cabildo de guisados de caballo, creado en torno al año 1420 como marco de asociación de los caballeros villanos, es decir de aquellos individuos de origen pechero que mantenían caballo y armas, y por ello disfrutaban de una serie de privilegios fiscales y políticos ${ }^{19}$.

Más adelante volveremos a tratar sobre las relaciones que el cabildo de caballeros y escuderos mantuvo con el de guisados de caballo, con el que compartió el derecho a designar uno de los dos procuradores a Cortes que tocaba enviar a la ciudad de Cuenca cada vez que éstas eran convocadas por el rey. Por el momento nos limitaremos a llamar la atención sobre algunos aspectos del régimen de funcionamiento de esta corporación, que nos permitan advertir mejor cuál era su perfil institucional. Así, en primer lugar se ha de destacar que disponía de un patrimonio que le proporcionaba rentas, aunque desconocemos en detalle cuál era su origen y composición. Sí nos consta que, al menos en parte, estas rentas se destinaron a la financiación de actividades piadosas $^{20}$, pero también hubo denuncias de apropiaciones indebidas llevadas a cabo por quienes estaban encargados de su administración ${ }^{21}$.

Al frente del cabildo había, conforme al modelo habitual en las cofradías, un preboste y cuatro "dados", que eran elegidos por un complejo

${ }^{18}$ Vid. José Antonio JARA FUENTE, Concejo, poder y élites. La clase dominante de Cuenca en el siglo XV, Madrid, CSIC, 2000, pp. 360-1. Indica este autor que la primera vez que se menciona el cabildo de caballeros y escuderos en las actas municipales es en 1442, aunque considera muy probable que existiese desde bastante antes.

${ }^{19} \mathrm{Vid} . \mathrm{M}^{\mathrm{a}}$ Dolores CABAÑAS GONZÁLEZ, La caballería popular en Cuenca durante la Baja Edad Media, Madrid, 1980. Y José Antonio JARA FUENTE, op. cit. pp. 363 y ss.

${ }^{20}$ AGS, RGS, I-1508, provisión al corregidor de Cuenca. Se hace constar que los propios del cabildo de caballeros y escuderos se suelen gastar en "obras pías" y no en salarios de oficiales del concejo.

${ }^{21}$ AGS, RGS, III-1506, fol. 201. El cabildo de caballeros y escuderos de Cuenca había denunciado que, teniendo éste propios y rentas, algunas personas se habían alzado con gran parte de las mismas, por lo que pedía que se tomasen cuentas a los que habían tenido cargo de su administración. Se ordeno al corregidor que lo hiciese. 
procedimiento. En concreto, según declaraciones efectuadas por el regidor Pedro de Alcalá en $1500^{22}$, para elegir al preboste el cabildo designaba a catorce personas, las que consideraba más hábiles, a efectos de que por sorteo se seleccionasen cinco de ellas, entre las cuales se volviese a realizar otro sorteo para determinar la persona que desempeñaría aquel año el oficio. Este mismo procedimiento se debía seguir en los sucesivos ejercicios, aunque excluyendo del sorteo a los individuos que ya hubiesen sido prebostes con anterioridad, para que finalmente las catorce personas inicialmente seleccionadas tuviesen ocasión de desempeñar el oficio. Y, por lo que toca a los cuatro "dados", le correspondía al preboste designar a dos de ellos, y al cabildo a los otros dos, aunque no sabemos por medio de qué procedimientos.

En cualquier caso la elección del preboste dio lugar a enconados conflictos, como el que se planteó en torno al año 1500, cuando el regidor Pedro de Alcalá denunció que desde hacía tres años el preboste Fernando de Jaraba, apoyado por otras personas, había dejado de respetar el procedimiento de elección tradicionalmente observado, que es el que acabamos de describir. Pero lo cierto es que por estas mismas fechas el teniente de corregidor, el bachiller Diego Blázquez, pronunció una sentencia sobre la elección del preboste de los caballeros y escuderos que fue suplicada por este mismo regidor, lo cual sugiere que no había consenso sobre el procedimiento que se había de seguir para la designación del oficial que había de estar al frente del cabildo, y que se trataba de un puesto muy ambicionado ${ }^{23}$.

\section{ENVÍO DE REPRESENTANTES \\ A LAS SESIONES DE AYUNTAMIENTO POR LAS CORPORACIONES DE CABALLEROS HIDALGOS}

La implantación del regimiento, que conllevaba la sustitución de los concejos abiertos por concejos cerrados, excluyó de la posibilidad de participar en la toma de decisiones en el principal órgano de gobierno local a la mayor parte de la población, tanto hidalga como pechera. En la práctica, sin embargo, durante bastante tiempo a las asambleas de concejo estuvieron asistiendo muchas más personas que las que por razón de su oficio debían hacerlo, aunque, por supuesto, el derecho de voto sólo podían ejercerlo unos pocos oficiales. Tras el acceso al trono de los Reyes Católicos estos monarcas realizaron, no obstante, un importante esfuerzo para conseguir que los concejos se hiciesen cerrados, y sólo pudiesen asistir a ellos las personas que por razón de su oficio estaban facultadas para ello. Por ello fue entonces cuando, como reacción, en bastantes ciudades las corporaciones de hidalgos se movilizaron para que al menos se les permitiese enviar procuradores que

\footnotetext{
${ }^{22}$ AGS, RGS, VI-1500.

${ }^{23}$ AGS, RGS, IX 1500.
} 
representasen los intereses de los miembros del estamento en dichas asambleas, pero no todas lo consiguieron en el mismo grado.

Desde esta perspectiva Soria destaca de nuevo por ser la ciudad en que la corporación local de caballeros hidalgos alcanzó mayor madurez institucional y política, pues durante el reinado de los Reyes Católicos ésta consiguió que se les reconociese el derecho a enviar regularmente tres diputados con voz y voto al ayuntamiento de concejo, que se habían de renovar todos los años, el cual continuó ejerciendo sin disputa hasta prácticamente el final del Antiguo Régimen a comienzos del siglo XIX. No sabemos con precisión a partir de qué momento se inició la práctica del envío de estos diputados que, en número de tres, reprentaban a los caballeros hidalgos de los doce linajes en la asamblea concejil, pero sí tenemos noticia de que en 1497 se intentó acabar con ella, después de que el año anterior los Reyes Católicos hubiesen prohibido terminantemente mediante real provisión que se continuasen celebrando concejos abiertos en la ciudad del Duero ${ }^{24}$. A raíz de ello Juan Morales y Juan de San Clemente, en nombre de los caballeros de los doce linajes, se desplazaron a la Corte para solicitar que se les respetase a éstos su derecho a enviar diputados a los ayuntamientos de concejo. Y consiguieron que los monarcas accediesen a su súplica, puesto que otorgaron en febrero de 1498 una nueva provisión en la que aclararon que lo dispuesto en la provisión del año anterior sobre los concejos cerrados no se debía entender en perjuicio del derecho que tenían los caballeros de los linajes de enviar representantes a dichas asambleas ${ }^{25}$. De este modo quedó entonces regularizada la práctica del nombramiento por los doce linajes de Soria de tres diputados, que con voz y voto debían representar los intereses de los miembros del estamento hidalgo en las asambleas concejiles. Estos diputados se renovaban todos los años, y, dado que habían de elegirse en número de tres, los doce linajes se distribuyeron para ello en cuatro grupos que se rotaron en su nombramiento.

En ninguna otra ciudad castellana lograron las corporaciones de hidalgos locales que se les reconociese una participación en la toma de decisiones en el principal órgano de gobierno local tan notable como en Soria. En algunas como Madrid es cierto que la presencia de numerosos caballeros hidalgos en las sesiones de concejo junto con los regidores y otros oficiales fue habitual a lo largo de todo el siglo XV, pues estaba contemplada en las disposiciones constitucionales vigentes. Así, en primer lugar, la sentencia de Montalvo de 1454 reconoció a los caballeros el derecho a asistir a las sesiones de ayuntamiento en que se tratasen cuestiones que les concernían a ellos como estamento. Y más adelante en la sentencia de concordia de Bobadilla de 1477 se les otorgó incluso mayor presencia en los ayuntamientos, restringiendo la posibilidad de que los regidores tratasen temas de interés general en los

\footnotetext{
${ }^{24}$ Esta provisión en AGS, RGS, IV-1497, fol.133.

${ }^{25}$ AGS, RGS, II-1498, fol. 73.
} 
consistorios secretos, a los que sólo podían asistir ellos ${ }^{26}$. Pero este fenómeno de fuerte presencia de caballeros hidalgos en el principal órgano de gobierno local madrileño, que resulta fácilmente perceptible a través de la lectura de los libros de actas, no fue acompañado de un paralelo proceso de consolidación y fortalecimiento de una organización estamental en la que se agrupasen todos ellos. Y esta circunstancia queda bien puesta de manifiesto en el hecho de que en esta ciudad no llegó a desarrollarse la figura institucional del procurador de los hidalgos, mientras que sí que lo hizo la del procurador de pecheros. Por supuesto a este respecto cabe matizar que, en contrapartida, existió la figura del procurador del concejo que, en virtud de lo dispuesto por la sentencia de concordia de Bobadilla de 1477, correspondía elegir a los caballeros. Pero, con todo, no dejaba de ser un procurador del concejo en su conjunto, en lugar de serlo del estamento privilegiado noble en particular. Y el régimen previsto para su designación tampoco dio lugar a que se consolidase una corporación estamental de los hidalgos propiamente dicha, ya que en la referida sentencia de concordia simplemente se dispuso que para su elección se observase un turno entre las parroquias, de modo que cada año correspondiese a una el designarlo, para lo cual deberían reunirse todos los caballeros que fuesen parroquianos de la misma y elegir entre ellos uno como procurador ${ }^{27}$.

Por el contrario en otras ciudades en que se restringió mucho más la presencia de caballeros hidalgos a título personal en las asambleas de concejo, sí llegó a regularizarse la práctica de admitir en las mismas un procurador del estamento hidalgo, que de este modo llegó a consolidarse como una importante figura institucional. Es el caso, por ejemplo, de Cuenca, donde durante el reinado de los Reyes Católicos el cabildo de caballeros y escuderos tuvo reconocido el derecho a designar todos los años un procurador que le representase en las sesiones de ayuntamiento, al cual, no obstante, debía pagar su salario con cargo a sus propias rentas, y no a las del concejo ${ }^{28}$. Por el contrario, en esta ciudad, el Común de pecheros no logró en este mismo período que se le reconociese similar derecho, de modo que sólo durante los meses de gobierno comunero en los años 1520 y 1521 pudieron acudir representantes de la población pechera conquense a las sesiones del ayuntamiento de concejo ${ }^{29}$. Y tampoco el cabildo de guisados de caballo pudo estar

\footnotetext{
${ }^{26}$ Carmen LOSA CONTRERAS, El concejo de Madrid en el tránsito de la Edad Media a la Edad Moderna, Dykinson, Madrid, 1999, p. 615.

${ }^{27}$ Carmen LOSA CONTRERAS, op. cit. pp. 349-51.

${ }^{28}$ AGS, RGS, I-1508. Provisión al corregidor de Cuenca. Se hace constar que hacía unos 8 años los Reyes Católicos había expedido una carta ordenando que hubiese en esa ciụdad un procurador del estado de los caballeros y escuderos, el cual "se obligase por la justicia y por el estado de los caballeros y escuderos", y llevase salario por razon de su oficio. A este procurador se le pagaba salario con cargo a los propios del cabildo del estado de los caballeros y escuderos, pero había habido quejas por ello, porque los propios de este cabildo se solían gastar en obras pías, y no en salarios de oficiales del concejo.

${ }^{29}$ Vid. Máximo DIAGO HERNANDO, El conflicto de las Comunidades en Cuenca (1520-

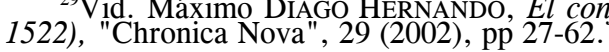


representado mediante procuradores en dichas sesiones ${ }^{30}$, circunstancia que resalta aún más el carácter privilegiado del tratamiento dispensado al cabildo de caballeros y escuderos.

Fuera de Cuenca también en otras ciudades el estamento hidalgo tenía reconocido a fines de la Edad Media el derecho a enviar un procurador a las sesiones de concejo, aunque tal derecho lo compartían con la Comunidad de pecheros. Es el caso significativo de Huete, donde a fines del siglo XV y comienzos del siglo XVI se observaba un régimen de reparto relativamente equitativo de oficios entre los estamentos pechero e hidalgo, sólo ligeramente favorable a este último ${ }^{31}$. Y también de Sepúlveda, donde las sesiones del concejo estaban abiertan a un elevado número de representantes de la población pechera e hidalga, tanto de la ciudad como de la Tierra ${ }^{32}$.

Otros muchos ejemplos se podrían añadir a estos dos, tomándolos sobre todo entre los núcleos urbanos de segundo rango, en los que el proceso de consolidación de cerrados grupos oligárquicos avanzó mucho menos que en las grandes ciudades. Pero aquí queremos llamar la atención sobre el hecho de que en bastantes de estas últimas no llegó a contemplarse la figura del procurador del estamento privilegiado hidalgo, y cuando se realizaron propuestas para su creación los regidores ofrecieron una fuerte resistencia a que la medida saliera adelante.

Para empezar cabe destacar el caso de Segovia, ciudad donde durante el reinado de los Reyes Católicos la Comunidad de pecheros tuvo reconocido el derecho a enviar dos procuradores a las sesiones de concejo, mientras que, paradójicamente, los linajes no consiguieron que se les hiciese extensivo también a ellos. Lo intentaron en 1498 cuando presentaron una petición a la monarquía para que autorizase a que en las reuniones del regimiento pudiese haber presentes uno o diputados de los linajes, que después informasen al conjunto de miembros del estamento sobre los asuntos tratados en dichas reuniones. Pero no lo consiguieron ante la frontal oposición de los regidores, que argumentaron que el incremento del número de personas asistentes a las reuniones dificultaría una gestión eficaz ${ }^{33}$.

\footnotetext{
${ }^{30}$ Tenemos constancia de que en 1442 se presentó una propuesta para que a las sesiones del ayuntamiento pudiesen asistir además del guardamayor, los oficiales de la justicia y los regidores, quince diputados de los cabildos de caballeros y escuderos, de guisados de caballo y de ciudadanos pecheros, con los mismos derechos y obligaciones que los primeros. Pero e proyecto no salio adelante debido a la oposición de los regidores. Vid. José Antonio JARA FUENTE, Sobre el conceio cerrado. Asamblearismo y participación política en las ciudades castellanas en la Baja Edad Media (Conflictos inter o intra-clase), "Studia Historica. Historia Medieval", 17 (1999), p. 126.

${ }^{31}$ José María SÁNCHEZ BENITO, El poder en una pequeña ciudad castellana: el ejemplo de Huete en el siglo XV, "En la España Medieval", 25 (2002), pp. 177-212.

${ }^{32}$ Algunas referencias en Carlos SÁEZ, Sepúlveda en la segunda mitad del siglo XV, "Anuario de Estudios Medievales", 9 pp. 2́67-326. Nos basamos también en documentación inédita del AGS, de las secciones RGS y Cámara-Pueblos.

${ }^{33} \mathrm{M}$. ASENJO GONZÁLEZ, op. cit. pp. 449-50. Ese mismo año también se solicitó que hubiese jurados en el regimiento, pero, de igual manera, los regidores se opusieron a que se introdujese esta nueva figura institucional, alegando que el incremento del numero de personas presentes en las reuniones del regimiento aumentaría la confusión. Ibídem, apéndice documental, pp. 631-636.
} 
También en Zamora los regidores ofrecieron resistencia a que en sus reuniones estuvieran presentes representantes tanto del estamento privilegiado de caballeros y escuderos hidalgos, como del Común de pecheros. Por virtud de lo dispuesto en la concordia del año 1499 se vieron obligados, no obstante, a acceder a admitirlos, como había sido la norma en tiempos pretéritos ${ }^{34}$. Pero algunos documentos de los años siguientes prueban que se continuaron mostrando remisos a cumplir lo acordado. Y así, por ejemplo, en 1505 se denunció que en el concejo zamorano se decidía con frecuencia la realización de repartimientos e imposición de sisas sin que estuviesen presentes representantes de los caballeros y escuderos hidalgos, y del "gremio y Común de pecheros", que no eran convocados para evitar que se opusiesen a la aprobación de tales medidas ${ }^{35}$.

En todos los casos mencionados la existencia de una bien consolidada organización corporativa de los miembros del estamento privilegiado hidalgo es la que hizo posible que se presionase a los regidores para admitir la presencia en el principal órgano de gobierno local de al menos un procurador de dicho estamento que velase por intereses de sus miembros, con diferente grado de éxito. En algunas ciudades, sin embargo, la existencia de tal corporación no propició la introducción de este oficio del procurador de los hidalgos, y ni siquiera dio lugar a ninguna campaña reivindicativa por parte de éstos para tratar de implantarlo. Así nos lo testimonia, por ejemplo, el caso de Valladolid, donde desde comienzos del siglo XIV los miembros del estamento privilegiado hidalgo estaban bien organizados en diez casas que se agrupaban en dos linajes, que tenían reconocidas importantes atribuciones en la provisión de varios oficios de gobierno local, entre los que destacaban los de regidores ${ }^{36}$. A pesar de ello, estas diez casas agrupadas en dos linajes, a diferencia de sus homólogas segovianas o sorianas, no mostraron interés, por lo que de momento sabemos, en verse representadas en las sesiones del ayuntamiento por otros oficiales que no fuesen los propios regidores, salidos de su seno. Y buena prueba de ello nos la proporciona el hecho de que, cuando en 1517 buena parte de la sociedad política vallisoletana se movilizó para tratar de conseguir que la monarquía autorizase a que dos procuradores de los pecheros pudiesen tener acceso a las sesiones del regimiento, los linajes de Tovar y Rehoyo se mantuvieron al margen, y tampoco solicitaron por su parte que se les autorizase a ellos a designar también procuradores, para contrarrestar al menos los efectos del logro alcanzado por el estamento pechero $^{37}$.

\footnotetext{
${ }^{34}$ Manuel Fernando LADERO QUESADA, La ciudad de Zamora en la época de los Reyes Católicos. Economía y gobierno, Zamora, 1991, pp. 124-33.

${ }^{35}$ AGS, RGS, VIII-1505, fol. 202.

${ }^{36}$ Vid. Adeline RucQuOI, Valladolid en la Edad Media, Valladolid, Junta de Castilla y León, 1987, 2 vols.

${ }^{37}$ AGS, RGS, VIII-1517. Provisión por la que se autorizó a la çiudad de Valladolid a designar todós los años dos procuradores que pudiesen entrar a las reuniones del regimiento en representación del estamento pechero, según se hacía en la ciudad de Burgos. Esta concesión se efectuó en respuesta a las peticiones presentadas por representantes del cabildo de la Iglesia 
En contrapartida, en otras ciudades podemos constatar un fenómeno de signo contrario, es decir, de fuerte movilización de los miembros el estamento hidalgo para conseguir una importante representación en el ayuntamiento de concejo, a pesar de no haberse dotado de una sólida organización corporativa. Éste sería a nuestro entender el caso de la ciudad de León, donde no tenemos noticia de que los caballeros hidalgos se hubiesen dotado en el transcurso de los siglos bajomedievales de una bien estructurada organización corporativa ${ }^{38}$. Esto no les impidió, sin embargo, poner en marcha en las vísperas del estallido de la revuelta comunera una ambiciosa campaña política, orientada a introducir profundos cambios en el régimen de gobierno local, que acabasen con el monopolio del ejercicio del poder del que venían disfrutando los regidores. En efecto, en 1518, según Joseph Pérez, tras regresar a León los procuradores que habían participado en las Cortes de Valladolid, se produjo en esta ciudad un intento de rebelión encabezado por los escuderos y caballeros, que en número de unos 50 se reunieron en una asamblea que reivindicó la ampliación del regimiento mediante la incorporación al mismo de cuatro representantes del estamento hidalgo, los cuales con su presencia contribuyesen a mitigar la prepotencia de los regidores ${ }^{39}$. Por otros documentos del Registro General del Sello hemos podido comprobar, no obstante, que los regidores acusaron a dos nobles en particular, Don Gutierre de Robles y Don Antonio de Quiñones, de haber sido los que, por afán de incrementar su poderío personal en la ciudad ${ }^{40}$, habían conspirado para poner en marcha este movimiento reivindicativo, que fue acompañado de graves alteraciones del orden público. En concreto sabemos que el regidor Luis Barba acudió a la Corte a denunciar que estos dos nobles habían reunido en torno a sí a unas 70 personas, con las que estaban provocando todo tipo de alborotos y desórdenes. En primer lugar habían lanzado una campaña difamatoria contra los procuradores enviados por la ciudad a las Cortes de Valladolid por haber otorgado el servicio solicitado por el rey, haciendo ver que si ellos hubiesen estado en el gobierno de la ciudad dicho servicio no se habría otorgado, y que, por no haber evitado su concesión, tanto los procuradores como los regidores que les habían otorgado los poderes debían ser considerados como traidores. Pero, no contentos con esto, andaban todos ellos juntos armados, de noche y de día, amenazando a los regidores, y haciendo "ligas y monipodios" contra ellos, procurando además enemistarles con el pueblo. Y, por fin, también se les acusaba de procurar que se autorizase a cuatro de ellos a entrar al

Mayor, de los monasterios, de la Universidad y de las 14 cuadrillas en que se agrupaba la población pechera.

${ }^{38}$ No proporciona noticias de su existencia José María SANTAMARÍa LuEngos, Señorío y relaciones de poder en León en la Baja Edad Media (Concejo y cabildo catedral en el siglo $X V)$, León, Universidad, 1993.

${ }^{39} \mathrm{Vid}$. Joseph PÉREZ, La revolución de las Comunidades de Castilla (1520-1521), Madrid, Siglo XXI, 1979, $3^{\mathrm{a}}$ ed. Pp. 120-1.

${ }^{40}$ En concreto los regidores denunciaron que Don Gutierre de Robles, que había fijado hacía poco tiempo su residencia en León, "con cóbdiçio y convinción de tener parte y mando en la ciudad" había inducido a D. Antonio de Quiñones para que se juntase con él. AGS, RGS, IV1518. 
ayuntamiento "para que los dichos regidores no tengan tanto poder, y haya quien contradiga los servicios"41.

Según el punto de vista de los regidores esta última pretensión no estaba justificada, teniendo en cuenta que la ciudad de León ya tenía un "procurador de la Comunidad" y otro procurador de los pecheros. Pero los caballeros y escuderos leoneses no participaban de este punto de vista, y, aunque el proyecto anunciado en 1518 de conseguir la admisión de cuatro diputados del estamento en las sesiones de ayuntamiento no salió adelante, continuaron presionando ante las instituciones de gobierno central de la monarquía para que les autorizase a tener algún tipo de representación en dicha asamblea de gobierno local, e incrementase su capacidad de intervención en la designación de oficiales de gobierno de rango menor, como eran, por ejemplo, los fieles. Así, nos consta que hacia mediados del año 1520, en pleno proceso de desencadenamiento de la revuelta comunera, Gutierre de Quirós y Lope de Castro, en nombre de los "caballeros, escuderos, oficiales y hombres buenos de León", acudieron a la Corte a denunciar que los regidores tenían por costumbre elegir de cuatro en cuatro meses por fieles de la ciudad a criados suyos y a personas que procuraban "más su provecho que el bien de la ciudad". En segundo lugar también se quejaron de que dichos regidores elegían cada año un procurador general, al que, cuando les parecía bien, concedían prórrogas para que pudiese desempeñar el oficio por uno o varios años más, y por este motivo los designados, para tratar de mantenerse durante el mayor tiempo posible en el ejercicio del oficio, se plegaban totalmente a la voluntad de los regidores, y no velaban por el bien de la ciudad en su conjunto, como era su obligación. Para acabar con estos males propusieron en primer lugar que en adelante los fieles no fuesen elegidos por los regidores sino por los caballeros, escuderos y hombres buenos, y, en segundo lugar, que se autorizase a los caballeros hijosdalgo de la ciudad a elegir todos los años un procurador y a los ciudadanos otro, para que ambos entrasen en el regimiento junto con los oficiales de la justicia y los regidores, de modo que éste no pudiese celebrarse sin su presencia, o, al menos, sin haberles convocado, debiendo estar igualmente presentes cuando se tomasen las cuentas de los propios y rentas de la ciudad, y de los repartimientos y sisas ${ }^{42}$.

No sabemos en qué quedaron estas propuestas de reforma del régimen de gobierno local de León que, por otra parte, se plantearon en uno de los momentos más convulsos de la historia castellana, cuando una parte importante de la sociedad política del reino se encontraba en abierta rebelión

${ }^{41}$ La relación de denuncias presentadas en la Corte por el regidor Luis Barba en nombre del concejo de León en AGS, RGS, IV-1518. Comisión al licenciado de Pomareda para que acudiese a León como juez pesquisidor para averiguar sobre la veracidad de las referidas denuncias. Vid. También AGS, RGS, VI-1518. Provisión al licenciado Pomareda, pesquisidor, comunicándole que el procurador de D. Antonio de Quiñones, Gutierre de Robles, Rodrigo de Villafañe, Pedro de Pardava y sus consortes, vecinos de León, había presentado una denuncia contra él, acusándole de haberse mostrado muy favorable a la parte contraria y muy odioso a sus representados, y por ello había solicitado que se remitiese la causa al Consejo Real.

${ }^{42}$ AGS, RGS, VII-1520. Provisiọ́n al corregidor de León, comisionándole para tomar información sobre la conveniencia de introducir las reformas propuestas. 
frente al rey. Lo más probable es que la derrota comunera impidiese que saliesen adelante, al iniciarse en la segunda mitad del año 1521 un proceso de reacción que en muchas ciudades nos consta que dio al traste con todas las reformas que se habían introducido en los meses previos, que habían tenido por objeto facilitar el acceso al ejercicio del poder a sectores hasta entonces apartados del mismo. En cualquier caso, como quiera que fuese, aquí nos interesa recalcar que los acontecimientos ocurridos en León a partir de 1518 nos demuestran que la falta de una corporación estamental bien organizada y consolidada no impidió el desarrollo de un importante movimiento reivindicativo por parte de los miembros del estamento hidalgo frente al regimiento. No obstante se ha de tener en cuenta también que, según algunos indicios, este movimiento fue alentado por algunos poderosos nobles en particular, impulsados por ambiciones personales, los cuales pudieron actuar como elemento aglutinante en torno al que se unieron los hidalgos descontentos con el régimen de gobierno vigente, que, de otro modo, quizás no habrían sido capaces de poner en marcha un movimiento reivindicativo de tales dimensiones, faltos como estaban de una organización corporativa que sirviese para canalizar sus demandas.

\section{PARTICIPACIÓN DE LAS CORPORACIONES DE HIDALGOS EN LA DESIGNACIÓN DE OFICIALES DE GOBIERNO LOCAL}

Como ya hemos indicado, el principal rasgo que caracteriza a las corporaciones de hidalgos consolidadas en numerosas ciudades castellanas en el período bajomedieval de las que nos estamos ocupando en el presente trabajo, y que las diferencia de otro tipo de asociaciones integradas igualmente por miembros del estamento privilegiado, como eran las cofradías en sus diversas variantes, radica en la capacidad que se les reconoció a dichas corporaciones de participar en la designación de determinados oficiales de gobierno, y, por consiguiente, en la regulación del acceso al ejercicio del poder en el ámbito local. El rango de los oficiales que pudieron designar estas corporaciones varió apreciablemente de unas ciudades a otras, pero entre ellos se contaron en bastantes de ellas algunos de los más influyentes, como trataremos de demostrar a continuación, dedicando especial atención a los oficios de procuradores a Cortes y regidores.

\section{Procuraciones a Cortes}

Entre los oficios más ambicionados de cuantos pudieron proveer las corporaciones de hidalgos en las ciudades castellanas bajomedievales se ha de destacar en primer lugar el de procurador de Cortes, por cuanto su desempeño conllevaba importantes beneficios económicos, y la posibilidad de obtener otro tipo de mercedes de la monarquía, siempre dispuesta a mostrarse generosa con los representantes de las ciudades en estas asambleas para así asegurarse su 
docilidad $^{43}$. A partir del siglo XV, sin embargo, sólo diecisiete ciudades conservaron el derecho a estar representadas en Cortes por dos procuradores cada una. Y entre éstas fueron relativamente numerosas las que otorgaron a las corporaciones de hidalgos en ellas constituidas algún tipo de papel en el proceso de selección de dichos procuradores.

El caso más extremo lo encontramos de nuevo en la ciudad de Soria, donde cada vez que el rey convocaba Cortes correspondía a los Doce Linajes de caballeros hijosdalgo elegir entre sus miembros a los dos procuradores. Para ello estos linajes se habían agrupado en cuatro grupos de tres, que se iban rotando en el ejercicio del derecho de designar a estos oficiales. Así, cada vez que el rey convocaba Cortes, se reunían los tres linajes a los que por turno correspondía en aquella ocasión tomar parte en el proceso de elección, y cada uno en su iglesia procedía mediante votación de todos los caballeros y escuderos que estaban inscritos en el linaje a designar un candidato. Dado, no obstante, que sólo se podían enviar dos procuradores, y los candidatos propuestos por los linajes eran tres, debía procederse después en una asamblea de concejo a realizar un sorteo para determinar cuál de los tres no podría actuar como procurador. Pero a éste, a pesar de no poder desempeñar personalmente el oficio, se le compensaba también con el derecho a participar a partes iguales en los provechos económicos que los dos procuradores obtuviesen por razón del desempeño de la procuración ${ }^{44}$.

A diferencia de Soria, en otras ciudades las corporaciones de caballeros hidalgos sólo pudieron tomar parte activa en el proceso de selección de uno de los dos procuradores a Cortes, mientras que la elección del otro correspondía a los regidores. Es el caso, en primer lugar, de Cuenca, donde, no obstante, el cabildo de caballeros y escuderos, que aglutinaba al sector más encumbrado de la sociedad política conquense, el de los hidalgos, hubo de compartir este derecho con otro cabildo, el de los guisados de caballo, en el que se integraban los individuos de origen pechero que, por estar en condiciones de combatir a caballo, participaban de bastantes de los privilegios de los miembros del estamento hidalgo, aunque no a título hereditario.

Estos dos cabildos, sin embargo, no consiguieron que se les reconociese en firme este derecho hasta 1450 , pues todavía ese año los regidores insistieron en que las dos procuraciones a Cortes debían recaer en ellos, conforme a la que consideraban costumbre tradicional de la ciudad. Los cofrades de los cabildos de caballeros y escuderos, por un lado, y de "guisados de caballo", por otro, reclamaron, no obstante, que se les reconociesen las mismas preeminencias que se reconocían en otras ciudades a los cofrades de instituciones similares, y se les asignase por consiguiente una procuración a Cortes. Para resolver este contencioso las dos partes enfrentadas

${ }^{43}$ Algunas reflexiones al respecto en Máximo DiAGo HERNANDO, La representación ciudadana en las asambleas estamentales castellanas: Cortes y Santa Junta comunera. Análisis comparativo del perfil sociopolitico de los procuradores, "Anuario de Estudios Medievales", 34/2 (2004), pp. 599-665.

${ }^{44}$ Vid. Máximo DiAgo HeRnANDo, Estructuras de poder en Soria a fines de la Edad Media, Valladolid, Junta de Castilla y León, 1993, pp. 83 y ss. 
recurrieron al arbitraje del obispo de Cuenca, Lope Barrientos, y del corregidor Juan Velázquez de Cuéllar, quienes el 25 de noviembre de 1450 pronunciaron una sentencia arbitral, por virtud de la cual asignaron una procuración a los regidores, y la otra a los dos cabildos conjuntamente ${ }^{45}$.

Respecto al procedimiento que a partir de entonces pusieron en práctica estos dos cabildos para designar al procurador a Cortes que les correspondía nombrar cada vez que esta asamblea era convocada por el rey, parece que consistió en que los cofrades de cada uno de los cabildos se reunían por separado, para designar tres representantes el cabildo de los caballeros y escuderos y dos el de los "guisados de caballo", entre los cuales posteriormente se procedería a realizar un sorteo para sacar al procurador ${ }^{46}$. De este modo el superior rango social de los cofrades del cabildo de caballeros y escuderos alcanzaba reconocimiento formal mediante la asignación de un representante más para entrar en el referido sorteo.

En cualquier caso se ha de resaltar que la procuración era considerada en última instancia como un bien perteneciente a los cabildos, y por ello se contemplaba que parte de los beneficios económicos que obtenía el procurador por razón de su desempeño revirtiesen a los mismos. En concreto tenemos constancia de que en el seno del cabildo de caballeros y escuderos estuvo en vigor una ordenanza que disponía que el procurador a Cortes nombrado por dicho cabildo debía cederle la tercera parte de lo que obtuviese por razón de mercedes que los reyes le hiciesen como tal procurador. Algunos de los individuos que desempeñaron este oficio se resistieron, sin embargo, a cumplir lo dispuesto en dicha ordenanza, y éste fue el caso de Andrés Pérez de Teruel, quien fue elegido como procurador para las Cortes de Burgos de 1512, recibiendo de los reyes por el desempeño de este oficio un salario de 100.000 mrs. A raíz de ello el cabildo y preboste del gremio de los caballeros y escuderos le reclamaron que, conforme a lo dispuesto por la ordenanza que sobre ello tenían aprobada, les cediese una tercera parte de dicha cantidad, pero él no accedió a hacerlo, y para su mayor seguridad consiguió que el rey Fernando el Católico otorgase una real cédula a su favor, ordenando que se le pagase íntegramente el salario. El cabildo por su parte, no obstante, también realizó sus gestiones en la Corte para defender su derecho a ingresar una tercera parte del mismo, iniciándose así un complejo proceso judicial, del que desconocemos el desenlace ${ }^{47}$.

La documentación no deja claro, sin embargo, si esta obligación de ceder la tercera parte de los provechos económicos derivados del ejercicio de

\footnotetext{
${ }^{45}$ Vid. José Antonio JaRA Fuentes, Concejo, poder, élites..., p. 363. Y M ${ }^{\mathrm{a}}$ Dolores CABANAA, op. cit. p. 34.

${ }^{46} \mathrm{M}^{\mathrm{a}}$ Dolores CABAÑAS, op. cit. p. 84. Y Juan Manuel CARRETERO ZAMORA, Cortes, monarquía, ciudades. Las Cortes de Castilla a comienzos de la época moderna (1476-1515), Madrid, Siglo XXI, pp. 327-328.

${ }^{47}$ Referencias a este conflicto entre Andrés Pérez de Teruel y el cabildo de caballeros y escuderos de Cuenca en AGS, RGS, V-1513. Provisión al corregidor de Cuenca a petición de Alonso "Carrillo, "como uno del pueblo y gremio del cabildo de caballeros y escuderos de Cuenca”. Y RG'S, III-1514 $\left(2^{\circ}\right)$. Provisión al cabildo y preboste del gremio de los caballeros y escuderos de Cuenca.
} 
la procuración al cabildo de caballeros y escuderos sólo se daba cuando quien la desempeñaba era miembro de este cabildo, pero no cuando la suerte la hacía recaer en un miembro del cabildo de "guisados de caballo". Es bastante probable que así ocurriese, y que en este segundo caso el derecho de participación en los provechos perteneciese a este último cabildo. Pero no disponemos de pruebas concluyentes para demostrarlo. En cualquier caso, como quiera que fuese, la noticia de la existencia de esta costumbre nos confirma hasta qué punto el ejercicio de los oficios públicos era concebido en las ciudades castellanas bajomedievales, más que como un servicio a la comunidad, como una fuente de provecho económico y medro personal. Y esta concepción alcanzaba su máxima expresión en las procuraciones a Cortes. En el caso concreto de Cuenca así lo corrobora igualmente el hecho de que también entre los regidores, a quienes estaba asignada una de las dos procuraciones, se observó la norma de que el que por sorteo resultaba elegido para desempeñar la función se debía comprometer a ceder al resto de regidores una tercera parte de los provechos económicos que obtuviese por razón de la misma ${ }^{48}$. Por otra parte el activo papel que el cabildo de caballeros y escuderos asumió en el proceso de selección de los procuradores de Cortes en Cuenca, hasta el punto de hacerse reconocer el derecho a participar en los provechos económicos derivados del ejercicio del cargo, demuestra el elevado grado de desarrollo alcanzado por esta organización corporativa del estamento privilegiado conquense.

No le fue, sin embargo, a la zaga otra organización corporativa peculiar de esta ciudad, el cabildo de "guisados de caballo", pues también consiguió que se le reconociese el derecho a participar en la selección de uno de los procuradores a Cortes. Pero conviene precisar que, como consecuencia de su posición de inferioridad en la escala jerárquica local, tan sólo pudo hacer entrar en los sorteos a dos de sus miembros, mientras que el cabildo de caballeros y escuderos tuvo reconocido el derecho a hacer entrar a tres. Y este tratamiento discriminatorio todavía se agudizó más en el año 1520, cuando la sociedad política conquense decidió enviar representantes a la Santa Junta comunera reunida en Tordesillas, pues de los cuatro procuradores designados por la ciudad, dos fueron elegidos por el estado de los caballeros y escuderos, dos por el estado de los "guisados de caballo", y un cuarto, Fernando de Alcocer, por el estado de la Comunidad, que con anterioridad nunca había participado en los procesos de elección de los procuradores a Cortes ${ }^{49}$.

Un modelo para la designación de estos oficiales bastante parecido al de Cuenca lo encontramos vigente a fines de la Edad Media en la ciudad de Zamora, donde las dos procuraciones se repartían por mitad entre el gremio

\footnotetext{
${ }^{48}$ Así según documento fechado en Cuenca, 28-III-1462, Álvaro de la Muela, hijo de Gonzalo Martínez de la Muela, voz y voto de regidor, se obligón a dar la tercera parte de los ingresos devengados por la procuracion al resto de regidores, en virtud de ordenanzas existentes al efecto. Cita este documento, conservado en el Archivo Municipal de Cuenca, César OLIVERA SERRANO, Inventario de la documentación medieval sobre las Cortes de Castilla y León en e archivo municipal de Cuenca (1250-1500), "En la España Medieval", 19 (1996), pp. 347-415.

${ }^{49}$ Vid. Máximo DiAgo HeRnAndo, El conflicto de las Comunidades en Cuenca...
} 
de los hidalgos, por un lado, y los regidores por otro. Para la provisión de la procuración asignada al gremio de los hidalgos se plantearon, no obstante, enconados conflictos en las primeras décadas del siglo XVI, que ofrece interés analizar para profundizar en el conocimiento del régimen de funcionamiento de esta corporación, que había alcanzado para entonces un elevado grado de desarrollo institucional. El origen de los conflictos estuvo en la decisión tomada hacia 1504 en el seno de este gremio para que en adelante todos los años cuatro caballeros hidalgos asumiesen la función de nombrar a las personas que habían de desempeñar los oficios y "mensajerías" que correspondiese proveer al mismo. Estos caballeros, identificados con el nombre de "cuatros", permanecerían en el ejercicio de sus funciones por períodos anuales, y al cesar nombrarían a su vez a sus sustitutos. Muchos miembros del gremio entendieron, sin embargo, que este procedimiento propiciaba una fuerte concentración de poder en manos de estos cuatro caballeros, y por ello en 1519, encabezados por el comendador Hernando de Porres y García López de Porres, reclamaron ante las instituciones centrales de gobierno de la monarquía su modificación, con el argumento de que generaba múltiples inconvenientes. En concreto solicitaron que en adelante se prohibiese la designación como "cuatros" de personas que viviesen con "caballeros", es decir, que formasen parte de la clientela de los nobles más influyentes de la ciudad. Y, en segundo lugar, propusieron que la designación de los "cuatro" entrantes no se dejase en manos de los salientes, sino que éstos se limitasen a designar dieciséis individuos miembros del gremio de los hidalgos para que entre ellos se determinase por sorteo quiénes habían de ejercer como "cuatros"50. Estas propuestas de reforma no fueron bien acogidas por otros sectores del gremio, y, como consecuencia, se inició un largo y complejo pleito ante el Consejo Real, que estaba en marcha cuando el rey Carlos I convocó a principios de 1520 las Cortes de Santiago. Por este motivo entonces la monarquía, a fin de evitar dilaciones, decidió intervenir, ordenando por real provisión que, sin perjuicio de lo que se decidiese en instancia judicial, en aquella ocasión fuesen los "cuatro" que ya había nombrados los encargados de proceder, conforme a la costumbre, a la elección del procurador que tocaba designar al gremio de los hidalgos ${ }^{51}$.

Además de en Cuenca y Zamora, también en Madrid los regidores tuvieron que ceder una de las dos procuraciones a Cortes a los miembros del estamento hidalgo, pues así quedó establecido en la sentencia arbitral de Alfonso Díaz de Montalvo de 1454. Pero en este caso no consta que en el proceso de elección de este segundo procurador, que no era regidor, interviniese ninguna corporación en la que estuviesen agrupados los miembros del estamento privilegiado madrileño, como hemos visto que ocurría en Cuenca y Zamora. Por el contrario, por lo que de momento sabemos, parece que en la villa del Manzanares la elección de este procurador se efectuaba en

${ }^{50}$ AGS, RGS, XI-1519. Comisión al corregidor de Zamora para que tome información.

${ }^{51}$ AGS, RGS, II-1520. Provisión al concejo de Zamora. 
el marco de las parroquias, que tenían establecido un turno, en virtud del cual cada vez que el rey convocaba Cortes correspondía a una de ellas designar a este oficial, para lo cual se reunían todos los hidalgos parroquianos de la misma, y entre ellos elegían al procurador ${ }^{52}$.

\section{Oficios de regidores vitalicios}

Junto con el oficio de procurador a Cortes, otro de los más apetecidos en las ciudades castellanas bajomedievales y modernas era el de regidor, no tanto por la remuneración económica que conllevaba sino más bien por sus atribuciones, que eran muy amplias y permitían a quienes lo desempeñaban controlar los principales resortes del poder local. La participación de las corporaciones de nobleza urbana en los procesos de selección de estos influyentes oficiales también estuvo en un primer momento bastante extendida en determinados ámbitos de la Corona de Castilla, muy en particular en el sector meridional de la submeseta norte, entre el Duero y el Sistema Central. Poco a poco, sin embargo, estas corporaciones fueron perdiendo capacidad efectiva de intervenir en dichos procesos, conforme se fueron generalizando las transmisiones de las regidurías de padres a hijos, y las renuncias de las mismas a favor de otros parientes o incluso de personas con las que el renunciante no estaba emparentado, en estos casos con frecuencia a cambio de dinero. Pero dichas corporaciones tardaron mucho tiempo en perder del todo sus atribuciones en este terreno, como bien lo demuestra, por ejemplo, el caso de los Doce Linajes de Soria, que, formalmente al menos, preservaron su derecho a designar a los regidores de esta ciudad hasta el fin del Antiguo Régimen.

Entre las ciudades con voto a Cortes, fue en Soria, en efecto, donde las organizaciones corporativas de la nobleza urbana, es decir, los Doce Linajes, desempeñaron un papel más activo en el proceso de designación de los regidores, pues era a ellas a las que correspondía proponer candidato al rey cada vez que un oficio quedaba vacante, y este último se limitaba a nombrar al caballero propuesto. Dado que hasta mediados del siglo XVI en esta ciudad el número de regidores estuvo litimado a tan sólo seis, los Doce Linajes estaban agrupados en parejas de dos que se turnaban en la provisión de una misma regiduría. Así, cuando un regidor fallecía, el linaje que formaba pareja con el linaje del difunto debía reunirse para designar entre sus miembros, mediante votación, un candidato para ocupar el oficio que había quedado vacante, que había de ser presentado al rey para su confirmación ${ }^{53}$.

Además de Soria, otras cuatro ciudades con voto en Cortes conocieron la institución del "linaje" como organización corporativa de la nobleza urbana, de la que los miembros del estamento privilegiado hidalgo se dotaron para

\footnotetext{
${ }^{52}$ Juan Manuel CARRETERo ZAMORA, Cortes, monarquía, ciudades. Las Cortes de Castilla a comienzos de la época moderna (1476-1515), Madrid, Siglo XXI, pp. 322-25.

${ }^{53}$ Vid. Máximo DiAGo HeRnANDO, Introducción a la historia institucional... Y, Estructuras de poder... pp. $186 \mathrm{y}$ ss. 
canalizar su participación en el ejercicio del poder en el ámbito local. Fueron Segovia, Valladolid, Ávila y Salamanca. Pero, a diferencia de Soria, no tenemos constancia de que en ellas los hidalgos que estaban adscritos a cada linaje participasen de forma activa en el proceso de selección de los candidatos a regidores, aunque, en contrapartida, al menos debía quedar garantizado que cada uno de los linajes estuviese representado en el ayuntamiento por igual número de estos oficiales. En concreto en Valladolid la mitad de los regidores debían ser miembros del linaje de Tovar y la otra mitad del linaje de Reoyo. Pero una buena prueba de que estos linajes no participaban en su selección la encontramos, por ejemplo, en el hecho de que en 1498 un tal Bernal Françés, miembro del linaje Tovar, fue nombrado regidor por el rey, en sustitución de Juan de Torquemada, miembro del linaje Rehoyo, y, para ser admitido al desempeño del oficio, se limitó a solicitar en el ayuntamiento que se le otorgase licencia para cambiar de linaje ${ }^{54}$. En Salamanca, en virtud de lo dispuesto en las ordenanzas de Sotos Albos, las regidurías se debían repartir a partes iguales entre los dos linajes de Maldonados y Tejadas. En Segovia, cuando Alfonso XI creó allí el regimiento dispuso que hubiese quince oficiales, de los cuales cinco deberían ser pecheros, dos en representación de la ciudad y tres en representación de la Tierra, y los otros diez caballeros, debiéndose repartir estos últimos por mitad entre los dos linajes de Día Sánchez y Fernán García. Y en Ávila, por fin, también parece que en los siglos XV y XVI los oficios de regidor se repartían por mitad entre los linajes de San Vicente y San Juan ${ }^{55}$, aunque hay noticias de que en algunos momentos hubo, además, al menos dos regidores pecheros ${ }^{56}$. Por lo que de momento sabemos, sin embargo, en ninguna de estas ciudades los linajes como corporaciones desempeñaron un papel activo en el proceso de elección de los regidores, sino que los oficios se proveyeron por otras vías, entre las que la más frecuente fue la transmisión de padres a hijos.

En el grupo mucho más numeroso de ciudades sin voto en Cortes, también hubo varias, ubicadas en su práctica totalidad en el sector meridional de la submeseta norte, en que las corporaciones de nobleza urbana llegaron a desempeñar un importante papel en el proceso de regulación del acceso al desempeño del oficio de regidor, que era el de mayor rango en las mismas, al no poder optar sus vecinos a las procuraciones a Cortes. No vamos a entrar aquí a ofrecer una relación pormenorizada de dichas ciudades, pero al menos, a título ilustrativo, nos referiremos brevemente a algunas de las que nos proporcionan ejemplos más interesantes de intervención de este tipo de

${ }^{54}$ Vid. F. PINO Rebolledo, Libro de Actas del Ayuntamiento de Valladolid. Año 1498, Valladolid, 1992, p. 55.

${ }^{55}$ En la ordenanza que aprobó el concejo de Ávila en 1515 para regular el proceso de elección de los procuradores a Cortes se dispuso que se hiciese por sorteo entre los regidores, echando en un cántaro papeletas con los nombres de los regidores del linaje de San Juan, y en otro con los nombres de los regidores, del linaje de San Vicente. Vid. Máximo DiAGO HERNANDO, Conflictos políticos en Avila en las décadas precomuneras, "Cuadernos Abulenses", 19 (1993), p. 73.

${ }^{56}$ Vid. José Ignacio MoREnO NÚÑEZ, Ávila y su Tierra en la Baja Edad Media (Siglos XIII$X V)$, Valladolid, Junta de Castilla y León, 1992, p. 5. 
instituciones en la provisión de oficios públicos de gobierno, como era el de regidor.

El mejor ejemplo de activa participación en la elección de regidores por las corporaciones de nobleza urbana entre las ciudades que no tenían voto en Cortes nos lo proporciona Olmedo, donde los miembros del estamento privilegiado hidalgo se distribuían en dos linajes, llamados "de dentro" y "de fuera". Cada uno de estos linajes tenía reconocido el derecho a nombrar a la mitad de los regidores perpetuos, es decir, vitalicios, que había en la villa. Así, cada vez que quedaba vacante una regiduría, por muerte o por inhabilitación de quien la desempeñaba, tocaba al linaje al que estaba adscrita la misma reunirse para proceder a la elección de un nuevo regidor. Dicha elección se llevaba a cabo conforme al mismo procedimiento previsto para el resto de oficios que tocaba proveer al linaje, tanto vitalicios como de renovación anual. En concreto, por virtud de lo dispuesto en las ordenanzas que en 1514 aprobó el linaje "de dentro", sabemos que para efectuar las dichas elecciones debían reunirse en asamblea todos los hidalgos miembros del respectivo linaje en la iglesia donde tenían por costumbre hacerlo. Tenían derecho a voto todos los hidalgos registrados en el libro de "matrícula" que fuesen mayores de 14 años, $\mathrm{y}$, aunque durante bastante tiempo se admitió que los ausentes pudiesen votar por delegación, las referidas ordenanzas del año 1514 del linaje "de dentro", para acabar con los abusos a los que esta práctica había dado lugar, dispusieron que en adelante sólo pudiesen votar los que acudiesen en persona a hacerlo al lugar de la asamblea, que en el caso de este linaje era la capilla de Santa Catalina de la iglesia de San Pedro. En cualquier caso el número de personas que llegaban a tomar parte en las elecciones, en las que se garantizaba el carácter secreto del voto mediante el uso de papeletas que se introducían en un cántaro, era relativamente elevado, pues, por ejemplo, en 1508 nos consta que uno de los candidatos, Diego de Troche, obtuvo 43 votos, mientras que su contrincante, Rodrigo de Vivero, consiguió $26^{57}$.

Un régimen parecido al de Olmedo estaba vigente en la cercana Medina del Campo, donde el número de linajes era, no obstante, mucho mayor, ya que alcanzaba los siete, a cada uno de los cuales correspondía proveer un oficio de regidor, mediante elección en la que participaban todos sus miembros. Y, una vez elegido, el regidor pasaba a convertirse en la máxima autoridad dentro del linaje, pues gozaba de ciertas preeminencias y era el encargado de convocar las asambleas, aunque en su ausencia podían hacerlo también los dos parientes más antiguos ${ }^{58}$.

Bastante más compleja era la situación que se daba a fines de la Edad Media en otros concejos como Arévalo o Ciudad Rodrigo, donde también las regidurías estaban adscritas a los linajes en que se agrupaban los miembros del

${ }^{57}$ Vid. Máximo DiAgo HeRnANDo, Documentos para la historia de los linajes urbanos castellanos. Las ordenanzas del linaje de dentro de Olmedo de 1514, "Tomás Quesada. Homenaje", Universidad de Granada, 1998, pp. 187-206.

${ }^{58} \mathrm{M}^{\mathrm{a}}$. Ișabel del VAl VALDIVIESO, Medina del Campo en la época de los Reyes Católicos, en "Historia de Medina del Campo y su Tierra", Valladolid, 1986, vol. I, pp. 288 y ss. 
estamento privilegiado hidalgo. En concreto en Arévalo había cinco linajes, y a cada uno de ellos estaban adscritos dos oficios de regidor. Pero no tenemos constancia de que la selección de los candidatos para desempeñar el oficio se efectuase por votación en las asambleas del linaje al que estaba adscrita la regiduría, como era la norma en Soria, Olmedo o Medina del Campo. Por el contrario, lo único que sabemos con seguridad es que, por virtud del privilegio que tenían concedido los cinco linajes de Arévalo, sólo los hidalgos miembros del respectivo linaje podían ser nombrados para ocupar alguno de los dos regimientos que éste tenía adscritos. Así lo demuestra lo ocurrido en 1509, cuando Juan de Osorio, vecino de Arévalo, fue nombrado regidor de esta villa por renuncia de Antonio de Miraval, quien ocupaba un linaje perteneciente al linaje de Brizones. A raíz de ello, sin embargo, los caballeros hidalgos de este linaje suplicaron del nombramiento ante el Consejo Real, alegando que Juan de Osorio no era miembro de dicho linaje, ni había sido recibido en él antes de ser nombrado regidor, por lo cual su nombramiento era nulo, ya que contravenía el privilegio según el cual las dos regidurías adscritas a cada linaje sólo podían ser ocupadas por hidalgos que fuesen miembros del mismo ${ }^{59}$. Por consiguiente no se cuestionaba la validez del procedimiento por el que Juan de Osorio había recibido su nombramiento, una renuncia a su favor por parte de quien desempeñaba el oficio, sino el hecho de que el beneficiario de la renuncia no era miembro del linaje, por lo cual no podía ser recibido como regidor. Y este hecho nos sugiere que, al menos para aquellas fechas, los cinco linajes de Arévalo no ejercían el derecho de seleccionar mediante votación a los regidores de la villa, si bien no hay que descartar que lo hubiesen ejercido en períodos anteriores.

Por lo que respecta a Ciudad Rodrigo sabemos que en esta ciudad había dos linajes, llamados de "Garcí López de Chaves" y de "Pacheco", que se repartían a partes iguales los doce oficios de regidores. Pero tampoco allí dichos linajes actuaban a fines de la Edad Media como asambleas electorales, al modo como lo hacían, por ejemplo, en Olmedo, puesto que cada vez que quedaba vacante un oficio de regidor eran los restantes regidores los que debían proceder a nombrar a su sustituto, garantizando siempre que el designado fuese hidalgo miembro del linaje al que estaba adscrita la regiduría que había quedado vacante. La documentación conservada aporta informaciones contradictorias sobre cuáles eran los regidores que debían llevar a cabo dicha elección, si todos ellos, es decir los de los dos linajes, conjuntamente y en igualdad de condiciones, o sólo los que eran miembros del linaje al que estaba adscrita la regiduría que había quedado vacante. Lo cierto es que, a juzgar por la documentación conservada en el Registro General del Sello, en las últimas décadas del siglo XV y en las primeras del XVI proliferaron en Ciudad Rodrigo las disputas entre candidatos que aspiraban a ocupar regimientos vacantes, que en muchos casos se tuvieron que dirimir en el

\footnotetext{
${ }^{59}$ AGS, RGS, VIII-1509. Emplazamiento a Juan Osorio, vecino de Arevalo, a petición de Beltran de Velasco y Francisco Verdugo, en nombre de los caballeros hidalgos del linaje de Brizones.
} 
Consejo Real. No podemos entrar aquí en un análisis pormenorizado de estos conflictos, que habría que realizar en el marco de un estudio de la lucha por el poder en Ciudad Rodrigo en el período precomunero. No obstante sí interesa destacar que, al margen de que no siempre se siguió el mismo criterio para dirimir las diferencias, prevaleció habitualmente el principio de que el candidato que había obtenido la mayoría de los votos de los emitidos por los regidores miembros del linaje al que estaba adscrita la regiduría en disputa era el que debía recibir el nombramiento ${ }^{60}$. De lo que no cabe duda, en cualquier caso, es de que las asambleas del conjunto de los hidalgos miembros de cada linaje no desempeñaban ningún papel en este proceso.

Un último ejemplo que queremos traer a colación para completar este breve panorama nos lo proporciona la villa de Tordesillas, donde también tenemos constancia de la participación de corporaciones de nobleza urbana denominadas linajes en la elección de regidores. En efecto, por una ejecutoria del Consejo Real de $1514^{61}$ sabemos que dos vecinos de esta villa vallisoletana, sometida al señorío de la abadesa del monasterio de clarisas allí ubicado, se habían disputado un oficio de regidor que había quedado vacante por muerte de Pedro de Vega. Poco después de producirse dicha muerte ciertos "parientes" del linaje de San Pedro presentaron en el concejo a Antonio de Vega, hijo del difunto, y pidieron a los miembros de la asamblea concejil que les diesen sus votos para que éste fuese "regidor de la villa y del dicho linaje de San Pedro". En respuesta a esta petición varios regidores manifestaron su intención de dar su voto al referido Antonio de Vega, quien en consecuencia fue recibido como regidor por el alcalde, el bachiller Bernal, quien le tomó juramento. Poco después, sin embargo, los regidores Julián Alderete y licenciado Rodrigo Alderete se presentaron ante el alcalde para manifestarle su intención de reunirse para proceder a la elección del sucesor del difunto regidor Pedro de Vega, y requerir a los regidores Hernando de Vega y Ramón de Vega que se juntasen con ellos a este efecto. El alcalde les respondió que ya se había elegido a Antonio de Vega, y que se había solicitado a la abadesa como señora de la villa que le confirmase. No sabemos cómo reaccionaron dichos regidores al recibir esta respuesta, pero sí nos consta que un grupo de "parientes" del linaje de San Pedro, en el que previsiblemente se integrarían los referidos dos regidores, procedieron a elegir como regidor al bachiller Gonzalo de Oviedo, y pidieron a la abadesa que le confirmase. Al parecer esta última, que no había accedido a confirmar de forma inmediata a Antonio de Vega cuando el alcalde solicitó su confirmación, se mostraba más inclinada

\footnotetext{
${ }^{60}$ Vid. por ejemplo AGS, RGS, IV-1516. Ejecutoria a favor de Pedro Álvarez Centeno en el pleito que trató con el comendador Alonso del Aguila sobre un regimiento de Ciudad Rodrigo. Pedro Alvarez Centeno había defendido el punto de vista de que era a los cinco regidores del linaje en que se producía la vacante a quienes correspondía designar al nuevo regidor, y así fue asumido por el Consejo. Real, que le otorgó a él la regiduría en disputa, a pesar de que el otro candidato había obtenido más votos, sumando los emitidos por regidores de los dos linajes. Vid también A. BERNAL ESTÉVEZ, El concejo de Ciudad Rodrigo y su Tierra durante el siglo $X V$, Salamanca, 1989, pp. $270 \mathrm{y}$ ss.

${ }^{61}$ AGS, RGS, XI-1514. Ejecutoria a petición de Antonio de Vega, vecino de Tordesillas, en el pleito que trató con el licenciado Gonzalo de Oviedo sobre un regimiento de la villa.
} 
a apoyar la candidatura del bachiller Gonzalo de Oviedo, de quien se dijo que era abogado del monasterio. Por ello tuvo finalmente que intervenir el rey Fernando el Católico, quien por real cédula dispuso que la abadesa se inhibiese y el asunto fuese examinado en el Consejo Real, donde finalmente se falló a favor de Antonio de Vega.

De todo esto podemos deducir, por tanto, que también en Tordesillas la elección de los regidores correspondía a linajes de características muy parecidas a los que existieron en otras villas del entorno, como Olmedo o Medina del Campo, aunque no sabemos con precisión cuál era su número. Y también son bastantes los indicios que prueban que en el proceso intervenían todos los miembros del correspondiente linaje, a quienes se alude como los "parientes", aunque no lo hacían de forma plenamente independiente sino en conjunción con varios regidores, que, no obstante, no sabemos con seguridad si eran todos los de la villa o sólo los que eran miembros del linaje en cuestión. Nuevas investigaciones centradas en la reconstrucción de la historia institucional de esta villa vallisoletana deberán aclarar estos extremos. Por el momento nos basta con lo dicho para dejar demostrado hasta qué punto estuvo extendida en el sector meridional de la submeseta norte la práctica de la participación de las corporaciones de nobleza urbana en los procesos de elección de regidores, aunque traducida en procedimientos muy diferentes de unas a otras.

\section{Otros oficios}

Aparte de los oficios de regidores y procuradores de Cortes, las corporaciones de hidalgos tuvieron reconocido también en numerosas ciudades el derecho a la elección de otros oficios de menor rango, en algunos casos de carácter vitalicio, como, por ejemplo, las escribanías, y en otros muchos de renovación anual. Así ocurrió, en primer lugar, en ciudades en que todos los miembros del estamento privilegiado se agrupaban en una única corporación. Es el caso de Zamora, donde al "gremio y ayuntamiento de caballeros e hijosdalgo" le correspondía proveer, además de una de las dos procuraciones a Cortes, dos de los cuatro "alcaldes del fuero" cuando no había corregidor en la ciudad; uno de los dos alcaldes de la Hermandad, cuatro de los ocho fieles; y la mitad de los mensajeros que se designaban para enviar a la Corte o a otros lugares. Y así lo sabemos por los conflictos que se plantearon en los primeros años del siglo XVI en torno a la regulación del procedimiento que se había de seguir en el seno de este gremio para la designación de las personas que habían de desempeñar todos estos oficios, tarea que, como ya adelantamos al hablar de las procuraciones a Cortes, se hacía recaer en cuatro caballeros que se designaban todos los años para este efecto ${ }^{62}$.

\footnotetext{
${ }^{62}$ AGS, RGS, XI-1519. Provisión dirigida al corregidor de Zamora, a petición del comendador'Hernando de Porres y García López de Porres, por sí y en nombre de los demás caballeros hijosdalgo vecinos de Zamora.
} 
En segundo lugar, también en la mayoría de las ciudades en que el estamento privilegiado hidalgo estaba organizado en dos corporaciones llamadas "linajes", éstas tuvieron reconocida la capacidad de participar en la elección de numerosos oficiales concejiles de muy diverso rango, aparte de procuradores a Cortes y regidores. Es el caso de Segovia, donde por virtud de la sentencia arbitral del año 1433 se dispuso que los regidores, por un lado, y los caballeros de los linajes, por otro, se repartiesen por mitad los cuatro oficios de alcaldes ordinarios, cuando no había en la ciudad corregidor ni justicia de fuera ${ }^{63}$, y los oficios de montaneros, encargados de la vigilancia de los términos de la Tierra. Los dos oficios de fieles deberían ser nombrados en adelante por los caballeros de los linajes, y, por fin, éstos se deberían turnar con los regidores para designar al alguacil y a quienes desempeñasen las "procuraciones e carreras e mandaderías", que se hiciesen por cuenta de la ciudad, de forma que un año los nombrasen los regidores y al siguiente los caballeros de los linajes ${ }^{64}$.

Otro ejemplo interesante, tomado del grupo de ciudades de segundo rango, nos lo proporciona Olmedo, donde los dos linajes en que se repartían los caballeros y escuderos hidalgos, el "de dentro" y el "de fuera", tenían reconocido el derecho a designar a las personas que habían de desempeñar los oficios de escribanos del número, que lo hacían a título vitalicio, y otros oficiales que se renovaban todos los años, los llamados "cadañeros", respecto a la identidad de los cuales no nos encontramos de momento bien informados, por falta de trabajos dedicados al análisis de la organización institucional de esta villa vallisoletana en el período bajomedieval ${ }^{65}$.

$\mathrm{Y}$, por fin, entre las ciudades en que el estamento privilegiado hidalgo estaba organizado en más de dos linajes, desde Trujillo, en que había tres, hasta Soria, donde alcanzaban el número de doce, los ejemplos de participación de estas corporaciones en la elección de oficiales concejiles de rango menor son también muy numerosos. De nuevo en el grupo de las ciudades de mayor rango político, las que tenían reconocido el derecho de enviar procuradores a Cortes, el mejor ejemplo nos lo proporciona la de Soria, donde los Doce Linajes, además de participar en la designación de procuradores a Cortes y regidores, procedían todos los años a nombrar cada uno de ellos un montanero, oficial encargado de la vigilancia de los términos realengos en el

\footnotetext{
${ }^{63}$ Una ocasión en que tenemos constancia de que los regidores por un lado y los caballeros y escuderos de los linajes por otro, procedieron a designar a los alcaldes ordinarios, dos los primeros y otros dos los segundos, fue cuando murió el corregidor Diego Ruiz de Montalvo, estando en el ejercicio de su oficio. Vid. AGS, RGS, VII-1514. Comisión al bachiller Francisco de León.

${ }^{64}$ Jesús MARTínez Moro, La Tierra en la Comunidad de Segovia. Un proyecto señorial urbano (1088-1500), Valladolid, Universidad de Valladolid, 1985, pp. 151 y ss. A fines del siglo XV los linajes denunciaron que el regimiento se tomaba para si todas las procuraciones, mensajeros y solicitadores que se enviaban a la Corte acerca de los negocios de la ciudad, cuando debian gozar de ellas un año los regidores y al siguiente año fos linajes. También denunciaron que les usurpaban las fieldades y las alcaldías de Hermandad, siendo suyas. Los regidores negaron en su replica de 14-VII-1498 que fuese cierto tanto lo uno como lo otro. Vid. M. ASENJO GONZÁLEZ, op. cit. pp. 631-636.

${ }^{65}$ Vid. Máximo Diago HeRnANDo, Documentos para la historia
} 
extenso territorio sometido a la jurisdicción de esta ciudad, y tres "alcaldes de Santiago", encargados de vigilar la dehesa de Valonsadero ${ }^{66}$.

En Medina del Campo, como en Olmedo, los linajes continuaban manteniendo a fines de la Edad Media el derecho a nombrar a los escribanos del número de la villa ${ }^{67}$, a razón de dos escribanos cada linaje, y además les competía el nombramiento de mayordomo, sayones, andadores y otros oficiales, para lo cual tenían establecido un turno entre ellos, que garantizaba el ejercicio ordenado de esta prerrogativa ${ }^{68}$. Y otro interesante ejemplo de participación de linajes en la elección de numerosos oficiales concejiles a fines de la Edad Media nos lo proporciona la ciudad extremeña de Trujillo, que desde este punto de vista representa un caso atípico, puesto que es de momento la única de la submeseta sur en la que tenemos constancia de la vigencia de esta práctica, que como ya hemos indicado, estuvo mucho más extendida en la submeseta norte. En concreto allí en el siglo XV los tres linajes de Altamiranos, Bejaranos y Añascos proveían ocho regimientos y dos fieldades, que eran los denominados "cargos mayores", y otros varios "cargos menores" como la "venta de hierbas", el "arca", la procuración, la abogacía, el "peso" y la "cuchara". Todos estos oficios, incluidos los de regidores, se elegían por períodos bianuales, con la condición de que quienes los desempeñaban no pudiesen ser reelegidos para ningún cargo hasta después de pasados dos años. Dentro de cada linaje había un pariente mayor que era quien al parecer influía de forma decisiva sobre el resultado de las elecciones, por lo cual se plantearon innumerables protestas, que llevaron finalmente a los Reyes Católicos a intervenir en 1491, disponiendo que en adelante dichas elecciones se efectuasen por medio de la insaculación, que se comenzó a aplicar a partir de $1494^{69}$.

No en todas las ciudades, sin embargo, en que los miembros del estamento privilegiado hidalgo consiguieron hacerse reconocer el derecho a participar en la elección de un importante número de oficiales concejiles, tales elecciones se llevaron a efecto en el marco de corporaciones estamentales bien estructuradas. Hubo algunas en que no ocurrió así, y que, por tanto, han de ser consideradas como excepciones a la norma, al menos en el estado actual

\footnotetext{
${ }^{66}$ Vid. Máximo Diago HeRnando, Introducción a la historia institucional...

${ }^{67}$ En otros lugares, como Arévalo, habían ejercido esta prerrogativa con anterioridad, pero la perdieron en el transcurso del siglo XV. Vid. J. de MONTALVO, De la historia de Arevalo y sus sexmos, Avila, 1928 , p. 254. Indica que los escribanos conservaron la facultad de designar escribanos hasta el siglo XV. También en Soria las doce escribanías del número estaban a mediados del siglo XIV vinculadas a los Doce Linajes, según se deduce de una provisión de Pedro I, otorgada en Sevilla, 22-III-1364, inserta en la ejecutoria del pleito de los escribanos contra el concejo de Soria, en Archivo de la Chancillería de Valladolid, Registro de Ejecutorias, C. 168, III-1502. Pero no consta que los linajes interviniesen activamente en el proceso de elección de dichos escribanos Vid. Máximo DIAGO HERNANDO La Extremadura soriana y su ámbito a fines de la Edad Media, Universidad Complutense, Madrid, 1992, pp. 58 y ss. y $1931-1933$.

${ }^{68}$ Vid. M ${ }^{\text {a }}$ Isabel del VAL VALDIVIESO, op. cit. p. 289.

${ }^{69}$ Carmen FERNÁNDEZ-DAZA ALVEAR, Linajes trujillanos y cargos concejiles en el siglo $X V$ "La ciudad hispánica durante los siglos XIII al XVI", Universidad Complutense, Madrid, 1985 , vol. I, pp. 419-432.
} 
de nuestros conocimientos. Éste sería el caso, en concreto, de Madrid, donde ya por virtud de la sentencia arbitral de Alonso Díaz de Montalvo del año 1454 se reconoció a los caballeros el derecho a participar en la elección de parte de los oficios públicos, que les fue ratificado en la Concordia de Bobadilla del año 1477, en la que además se arbitró un sistema de elección por collaciones para los mismos ${ }^{70}$. Como consecuencia fueron las asambleas de parroquia de los caballeros y escuderos hidalgos las que a fines del Medievo se consolidaron como marcos básicos para la participación en la vida política de los miembros de este estamento en Madrid, lo cual impidió que éstos se dotasen de una organización corporativa propia, de características similares a las de las que entonces proliferaron en otras muchas ciudades castellanas del entorno.

\section{REACTIVACIÓN DEL PAPEL POLÍTICO \\ DE LAS CORPORACIONES DE HIDALGOS \\ EN EL PERÍODO PRECOMUNERO}

El proceso de consolidación del sistema de gobierno oligárquico que tuvo lugar en las principales ciudades castellanas durante el reinado de los Reyes Católicos, con decidido apoyo de la propia monarquía, propició que con el transcurso del tiempo fuese cundiendo el descontento en amplios sectores de la sociedad política, disconformes con un régimen que les negaba de forma sistemática todo tipo de participación en la toma de decisiones en el ámbito local. Como consecuencia se produjo en las dos primeras décadas del siglo XVI un proceso de intensificación de los conflictos políticos en un importante número de ciudades, en los que alcanzaron particular protagonismo las organizaciones corporativas del estamento pechero, pilotadas en muchos casos por mercaderes y hombres de negocios que conformaban una "elite" con fuertes ambiciones políticas ${ }^{71}$. Además de las organizaciones corporativas pecheras, no obstante, en bastantes ciudades también tomaron parte en este proceso de desafío a las oligarquías las organizaciones corporativas de los hidalgos, que en varios casos experimentaron entonces una cierta revitalización de su papel político, después de muchas décadas de declive del mismo como consecuencia del progresivo fortalecimiento de la posición de los regidores frente a las corporaciones de las que procedían.

Un buen ejemplo en este sentido nos lo proporciona la ciudad de Segovia, donde la Junta de Nobles Linajes puso en marcha numerosas iniciativas contra la acción de gobierno de los regidores, a algunas de las cuales ya hemos hecho breve referencia con anterioridad. La profesora Asenjo llamó en su momento la atención sobre este fenómeno, al advertir una cierta

\footnotetext{
${ }^{70}$ Vid. Carmen LOSA CONTRERAS, op. cit. p. 615.

${ }^{71}$ Vid. Máximo DiAgo HeRnANDO, Transformaciones en las instituciones de gobierno local de las ciudades castellanas durante la revuelta comunera (1520-1521), "Hispania", 214 (2003), pp. 623-656
} 
revitalización de esta corporación a fines del siglo $\mathrm{XV}$, que se tradujo en la reclamación al regimiento de mayor libertad para reunirse, mayor representatividad en el concejo, y mayor capacidad de participación en tareas hasta entonces de exclusiva competencia del cabildo de regidores ${ }^{72}$. A pesar de que la mayor parte de las reivindicaciones presentadas por dicha Junta ante las instituciones centrales de gobierno de la monarquía no prosperaron, como consecuencia de la resistencia ofrecida por los regidores, los caballeros hidalgos de los linajes segovianos no se arredraron, y continuaron con su política de oposición a la acción de gobierno de estos oficiales que concentraban en sus manos prácticamente todo el poder en el ámbito local, que se intensificó en los años previos al estallido de la revuelta comunera. Así, como ejemplo ilustrativo de esta actitud, haremos breve referencia a algunas de las acciones por ellos emprendidas, de las que tenemos noticia a través de la documentación del Registro General del Sello.

En concreto hemos podido constatar que en noviembre de 1518 se expidieron numerosas provisiones a petición de los caballeros y escuderos de los Linajes de Segovia, en su mayoría relativas a denuncias presentadas por éstos contra las actuaciones de los regidores ${ }^{73}$. En una se les acusaba a éstos de no garantizar el cumplimiento de una provisión anterior por la que se ordenaba que no se consintiese sacar madera fuera de Segovia y su Tierra. En otra se recogía su denuncia de que el concejo había dado licencia para que anduviesen cabras por los montes y pinares de la Tierra, como consecuencia de lo cual éstos habían recibido mucho daño, en especial el de Valsaín, en el que por ello solicitaron que no se autorizase en adelante la entrada de cabras. En una tercera provisión se daba respuesta a la petición presentada por los Linajes para que en adelante se prohibiese a los regidores segovianos repartir la leña de los pinares de Valsaín sin consentimiento suyo, pues con la política de repartos que estaban practicando estaban causando la destrucción de dichos pinares. En una cuarta provisión se daba respuesta a la petición de los caballeros y escuderos de los Linajes para que en adelante se nombrasen como guardas de los montes y pinares de la Tierra personas "hábiles y suficientes", que no fuesen criados ni "allegados" de los regidores ni de los caballeros de los Linajes, pues, por serlo todos los que en aquellos momentos se estaban nombrando, los dichos montes y pinares estaban recibiendo mucho daño, al no atreverse los guardas a multar a los criados de sus amos, ni de los amigos y parientes de éstos. En este caso, por lo tanto, la petición de la corporación de los hidalgos segovianos no se dirigía exclusivamente contra los regidores sino también contra algunos caballeros que, sin serlo, ocupaban una destacada posición social que les confería una evidente influencia, de la que podían tender a abusar. Y este hecho nos demuestra que dentro de la propia

\footnotetext{
${ }^{72}$ M. ASENJO GONZÁLEZ, op. cit. pp. 293 y ss.

${ }^{73}$ Todas estas provisiones, al contenido de las cuales nos referiremos a continuación, en AGS, RGS, XI-1518. 
corporación debían existir tensiones y conflictos de intereses, pues no hemos de olvidar que en ella coexistían caballeros y escuderos.

En esta misma línea apunta, por otra parte, el contenido de otra provisión expedida a petición de los caballeros y escuderos de los Linajes de Segovia, representados por Diego de Contreras, que habían denunciado que los elegidos para desempeñar los oficios de fieles no los querían servir en persona sino que los cedían a otros individuos "de poca suerte y no abonados", por dineros que les daban, los cuales no los desempeñaban correctamente y cometían graves irregularidades. Por ello exigían que en adelante se eligiesen como fieles personas "hábiles y abonadas", y que aquéllos a quienes tocase el oficio por suerte lo sirviesen en persona. Por virtud de la sentencia de concordia de 1433 correspondía a los dos linajes nombrar a los dos fieles de la ciudad, y éstos al parecer lo hacían por medio de sorteo entre sus miembros, si bien más adelante los reyes dispusieron que hubiese otros dos fieles de la Comunidad. No sabemos muy bien si esta iniciativa de los caballeros y escuderos apuntaba precisamente contra estos fieles designados por la Comunidad, o contra todos los fieles en general, incluidos los que procedían de las propias filas de los linajes. Del tenor del documento no se deduce que se estableciesen distinciones entre unos y otros, y esta constatación invita a presumir que dentro del estamento, o, más exactamente, de la corporación, existían tensiones entre unos sectores más cercanos al poder y otros alejados del mismo. Pero en cualquier caso estas tensiones palidecían ante las mucho más graves entonces existentes entre los regidores por un lado, y los caballeros y escuderos de los linajes por otro.

De forma mucho menos intensa que en Segovia, también en Soria tuvo lugar en las décadas precomuneras una cierta movilización política de los miembros del estamento hidalgo más apartados del ejercicio del poder, aunque sus acciones de desafío a los regidores palidecieron ante la continuidad y radicalismo de las lanzadas contra estos mismos oficiales desde el Común de pecheros. Estas acciones fueron acometidas en muchos casos por determinados hidalgos en particular, y tuvieron, por tanto, un fuerte componente personalista ${ }^{74}$. Pero también hubo algunas en las que las corporaciones tuvieron un mayor protagonismo. Así ocurrió, por ejemplo, cuando en 1518 se trató de aprovechar la designación por Carlos I del comendador Aguilera como regidor acrecentado para conseguir que la monarquía incrementase el número de oficios de regidor en Soria de seis a doce, de manera que cada linaje pudiese designar en adelante su propio regidor. En aquella ocasión cada uno de los seis linajes que no estaban representados en el regimiento nombró en sus asambleas un procurador para que acudiese a la Corte a presentar allí la solicitud del incremento de regidurías ${ }^{75}$. Pero también hay que destacar que no lo hicieron, manteniéndose totalmente al margen, los seis linajes de los que

\footnotetext{
${ }^{74}$ Algunos ejemplos en Máximo Diago Hernando, Estructuras de poder en Soria... pp. 237 y ss.

${ }^{75}$ AGS, Consejo Real, leg. 41, fol. 13.
} 
procedían los seis regidores del número que entonces había en Soria, lo cual nos da idea de hasta qué punto la autoridad que estos oficiales ejercían en el seno de sus linajes podía llegar a ser grande. En cualquier caso el procurador del estamento hidalgo en su conjunto, Hernando de Barrionuevo, el mozo, quien dijo actuar "en nombre de los linajes de los caballeros que entran en el ayuntamiento de Soria", es decir de los tres diputados de los linajes que, como hemos indicado, tenían voz y voto en las asambleas de concejo, también se alineó en esta ocasión en contra de los regidores. Y este hecho nos confirma en la impresión de que tuvo lugar en aquella ocasión una movilización masiva del estamento privilegiado en contra de los regidores que conformaban el "núcleo duro" del grupo oligárquico, los cuales sólo lograron mantener al margen de la misma a sus propias clientelas. Pero tal movilización no dio lugar a ningún resultado positivo, puesto que los regidores sorianos, aunque no lograron impedir que tomase posesión de su oficio el comendador Aguilera, nombrado directamente por el rey como regidor acrecentado, sí evitaron que la monarquía autorizase la duplicación del número de regidurías, que no llegó a hacerse efectiva hasta $1543^{76}$.

También en Zamora se produjeron tensiones entre el grupo oligárquico de los regidores y la corporación en que se agrupaban los miembros del estamento privilegiado hidalgo durante las dos primeras décadas del siglo XVI, a pesar de que ambas partes habían llegado a un importante acuerdo a raíz de la firma de la concordia de 1499, que fijaba el procedimiento de reparto de los oficios entre unos y otros. Pronto, en efecto, los caballeros hidalgos comenzaron a denunciar que los regidores incumplían los acuerdos a los que se había llegado sobre la forma de proceder en la designación de las personas enviadas como "mensajeros" a la Corte, que preveían que se alternasen en su nombramiento los regidores y el gremio de los caballeros y escuderos. A raíz de estas denuncias el Consejo Real intervino ordenando que se cumpliese la capitulación, de manera que el mensajero fuese una vez regidor, y a la siguiente caballero-hidalgo. Entonces los regidores contraatacaron, denunciando que en el seno del gremio de los caballeros hidalgos se estaban cometiendo graves irregularidades, porque con frecuencia en sus asambleas eran elegidos para el desempeño de los oficios que correspondía designar al gremio individuos que no eran idóneos, pues se había llegado a nombrar a veces a personas que venían de linaje de "plebeyos", resultando como consecuencia perjudicados los "hidalgos verdaderos y antiguos y notorios". A esta denuncia los representantes del gremio respondieron que, en función de lo dispuesto en la capitulación que habían firmado con los regidores, bastaba para poder gozar de los oficios que correspondía designar al dicho gremio con ser caballero hidalgo, y vivir "en honra y hábito de hidalgos", "sin averiguar ni examinar más los linajes", es decir sin entrar a

\footnotetext{
${ }^{76}$ Vid. Máximo Diago HeRnANdo, Estructuras de poder en Soria, pp. 241-3. Sobre la ampliación del número de oficios de regidor en Soria a doce Vid. Máximo DiaGO HERNANDO Caballeros y ganaderos. Evolución del perfil socioeconómico de la oligarquía soriana en los siglos XV y XVI, "Hispania", 184 (1993), pp. 451-495.
} 
discriminar entre miembros de linajes antiguos e hidalgos de origen más reciente. Y finalmente fue éste el punto de vista que prevaleció, puesto que en la ejecutoria del Consejo Real que puso fin al pleito entre ambas partes, expedida en octubre de 1511, se dispuso que las personas elegidas para los oficios por el gremio de los caballeros bastaba con que fuesen "hábiles y suficientes", pero no era requisito indispensable que también fuesen hidalgos "de linaje antiguo"77.

Al conflicto entre regidores y caballeros hidalgos apartados del regimiento por el reparto de esferas de poder se superpuso, por tanto, en esta ocasión otro conflicto interno en el seno del propio gremio de los caballeros hidalgos, en el que trataron de interferir los regidores apoyando a una de las partes enfrentadas, en concreto a los hidalgos pertenecientes a linajes antiguos, que, al parecer, trataban de poner freno al ascenso en el seno de la corporación de individuos de origen pechero que habían conseguido convertirse en hidalgos de facto. Las razones por las que lo hicieron resultan difíciles de precisar, pero cabe aventurar que percibiesen en estos individuos dotados de un fuerte espíritu emprendedor, que es el que les habría permitido ascender en la escala social, una grave amenaza para su posición de control excluyente del ejercicio del poder local, por su mayor inclinación al activismo político. En este sentido cabe apuntar la hipótesis de que este relativo aperturismo del gremio de los hidalgos hacia personas que no eran en origen hidalgos, pero que, gracias a haberles sonreído la fortuna, habían llegado a ser reconocidos como tales, debió tener como consecuencia un cierto "descabezamiento" del Común de pecheros, que se vería privado de sus dirigentes más dinámicos y ambiciosos. Y por este motivo en Zamora el mayor desafío al grupo oligárquico de los regidores habría venido en las primeras décadas del siglo XVI no del Común de pecheros sino del propio gremio de los caballeros hidalgos, al que se habrían ido incorporando la mayoría de los individuos que en otras ciudades dieron cuerpo a la llamada "elite del Común". En el estado actual de nuestros conocimientos sobre la historia política zamorana del período precomunero resulta arriesgado asumir sin más la veracidad de estas hipótesis, pero no estaría de más tenerlas en cuenta en futuros trabajos de investigación para avanzar en la comprensión del sentido de los procesos que tuvieron lugar en Castilla en el período previo al estallido de la revuelta comunera.

En cualquier caso un hecho indiscutible es que después de 1511 los conflictos internos en el seno del gremio de los caballeros hidalgos de Zamora continuaron, e incluso se agravaron en las vísperas del estallido de la revuelta comunera, cuando se estaba tramitando en el Consejo Real un pleito para fijar el procedimiento que se había de seguir en la designación de los "cuatros" encargados de elegir a las personas que habían de desempeñar los oficios que tocaba proveer al gremio, del cual ya hemos dado cuenta al referirnos a las procuraciones a Cortes. Pero paralelamente se siguieron arrastrando los

\footnotetext{
${ }^{77}$ La ejecutoria puede consultarse en AGS, RGS, X-1511.
} 
enfrentamientos del gremio con los regidores, de los que nos da testimonio, por ejemplo, una provisión del año 1519 relativa a una petición presentada por el procurador de los caballeros hidalgos para que se les diese traslado de una ordenanza antigua que trataba sobre los fieles y sobre poner precio a la carne y el pescado, que necesitaban para presentar ante el corregidor por razón del pleito que entonces seguían con el concejo ${ }^{78}$.

Respecto a la movilización política de los hidalgos que tuvo lugar en la ciudad de León en el año 1518, ya hemos hecho alusión a la misma al tratar sobre la práctica del envío de diputados por este estamento a las asambleas de concejo, por lo que no vamos a reincidir aquí en el asunto. Simplemente resaltar que en este caso la movilización tuvo lugar a pesar de no existir en la ciudad una madura organización corporativa de este estamento. Y desde este punto de vista ofrece un importante contraste con todos los ejemplos mencionados con anterioridad. No obstante, también se ha de tener en cuenta que hay motivos para sospechar que detrás de esta movilización estuvieron dos nobles, Gutierre de Robles y Don Antonio de Quiñones, impulsados por ambiciones personales, que consiguieron arrastrar tras de sí a un importante número de hidalgos. Desde este punto de vista quizás habría que ver en este episodio una mera manifestación de un conflicto de bandos en el seno del grupo oligárquico leonés. Pero de momento, a falta de realizar más comprobaciones, no podemos estar seguros de si tuvo alguna relación con el enfrentamiento entre los Guzmanes comuneros y los Quiñones realistas que se desencadenó en León meses después, durante la revuelta comunera ${ }^{79}$.

Mucho peor informados estamos sobre la actitud política de los hidalgos apartados del ejercicio del poder en otras ciudades castellanas durante las primeras décadas del siglo XVI. Se echan en falta estudios monográficos dedicados al análisis de la evolución de la vida política en dichas ciudades en este convulso período. En cualquier caso disponemos de indicios que prueban que fueron muchas las ciudades en que se produjeron tensiones entre los mismos y los regidores. Y este fenómeno no se produjo sólo en aquéllas en que los hidalgos estaban dotados de sólidas corporaciones de nobleza urbana. Así, por poner un segundo ejemplo, además del de León, nos referiremos brevemente a Guadalajara, ciudad en la que según Pablo Sánchez León no llegó a consolidarse tal género de corporación ${ }^{80}$. A pesar de ello tenemos constancia de que sí se dieron circunstancias que pudieron contribuir a

\footnotetext{
${ }^{78}$ AGS, RGS, XI-1519. Provisión dirigida a Antonio de Ledesma, escribano del número de Zamora. Vid. también AGGS, RGS, X-1519. Se hace constar que hay pleito pendiente en el Consejo Real entre el concejo, justicia y regidores de Zamora de una parte, y el gremio de los caballeros hijosdalgo de la ciudad de otra, "sobre razón de poner del pescado fresco que se viene a vender a la ciudad, y otras causas".

${ }^{79}$ Vid. Eloy DíAZZ-JIMÉNEZ Y MOLLEDA Historia de los comuneros de León y de su influencia en el movimiento general de Castilla, Madrid, 1916. Y Eloy BENITO RUANO, Nuevos documentos sobre el movimiento de las Comunidades en León, "Archivos Leoneses", 29 (1975), pp. 3-20.

${ }^{80}$ Vid. Pablo SÁnCHEZ LEÓN, Absolutismo y Comunidad. Los orígenes sociales de la guerra de los comuneros de Castilla, Madrid, Siglo XXI, 1998.
} 
conferir cierta cohesión al estamento, como, por ejemplo, el hecho de que sus miembros llegaron a ser los legítimos perceptores de un derecho que se cobraba al ganado que pasaba por la ciudad. En efecto, sabemos que Pedro González de Mendoza y su mujer Aldonza de Ayala recibieron del rey por merced el referido derecho, y ellos a su vez donaron un tercio del mismo a los caballeros y escuderos de la ciudad, aunque la carta de donación estuvo largo tiempo perdida, y se plantearon muchos problemas para su recuperación, que seguían sin resolverse en $1505^{81}$.

Pero, cualesquiera que fuese el grado de cohesión alcanzado por el estamento hidalgo en Guadalajara, de lo que sí tenemos constancia es de que entró en ocasiones en abierto conflicto con los regidores. Así ocurrió, por ejemplo, en 1514, cuando Alonso de Arellano, por sí y en nombre de los demás caballeros vecinos de Guadalajara, denunció que hacía poco tiempo los regidores, "por mala intención y por particulares odios e intereses", habían aprobado unas ordenanzas prohibiendo a los caballeros que tomasen leña para provisión de sus casas en los montes de la ciudad, a pesar de que siempre habían tenido costumbre de poder hacerlo, con una o dos acémilas ${ }^{82}$.

La intensificación de la actividad política de las corporaciones de hidalgos que tuvo lugar en las ciudades castellanas en las dos primeras décadas del siglo XVI alcanzó su culminación en muchas de ellas durante los meses de la revuelta comunera en 1520 y 1521, aunque el apoyo prestado por estas corporaciones a la causa de los rebeldes no fue tan decidido ni tan generalizado como en el caso de las corporaciones de pecheros. Tras el aplastamiento de la rebelión tuvo lugar en las ciudades que más activamente habían participado en la misma un evidente reforzamiento de la posición política de los regidores, y como consecuencia el proceso de afianzamiento de las corporaciones de caballeros y escuderos hidalgos como activos protagonistas de la vida política local quedó allí frenado. Pero no es cierto, sin embargo, como ha llegado a afirmar de forma categórica Sánchez León, que entonces la monarquía suprimiese las corporaciones de caballeros urbanos allí donde éstas habían logrado previamente consolidarse ${ }^{83}$. Éstas persistieron en muchas ciudades, aunque ciertamente mucho más debilitadas, pero no es éste el lugar de entrar a demostrarlo de forma pormenorizada.

Fecha de recepción del artículo: marzo 2006.

Fecha de aceptación y versión final: junio 2006.

\footnotetext{
${ }^{81}$ AGS, Cámara-Personas, leg. 26. Provisión de los Reyẹs Católicos de Toro, 15-III-1505, dirigida a los alcaldes de Guadalajara., a petición de Francisco de Medina, como procurador Suárez de Avila, Ramir Núnez de Guzmán, Juan de Orozco y otros vecinos.

${ }^{82}$ AGS, RGS, XI-1514. Provisión a los alcaldes ordinarios de Guadalajara.

${ }^{83}$ Pablo SÁnCHEZ LeÓn, Absolutismo y Comunidad... pp. 295-6.
} 